\title{
Can Tropical Pacific Winds Enhance the Footprint of the Interdecadal Pacific Oscillation on the Upper-Ocean Heat Content in the South China Sea?
}

\author{
FUAN XIAO \\ School of Geographical Sciences, Guangzhou University, and State Key Laboratory of Tropical Oceanography, South China \\ Sea Institute of Oceanology, Chinese Academy of Sciences, Guangzhou, China \\ DONGXIAO WANG \\ School of Marine Sciences, Sun Yat-Sen University, and Southern Marine Science and Engineering Guangdong Laboratory, \\ Zhuhai, China \\ LEI YANG \\ State Key Laboratory of Tropical Oceanography, South China Sea Institute of Oceanology, Chinese Academy of Sciences, \\ Guangzhou, China
}

(Manuscript received 11 September 2019, in final form 25 February 2020)

\begin{abstract}
In this study, an enhanced footprint of the interdecadal Pacific oscillation (IPO) on the upper-ocean heat content (OHC) in the South China Sea (SCS) since the 1990s is revealed. The negative OHC-IPO correlation is significant $(r=-0.71)$ during 1990-2010 [period $2(\mathrm{P} 2)$ ], whereas it is statistically insignificant during 196080 [period 1 (P1)]. Analyses show that the scope of the equatorial Pacific wind anomalies is wider during P2 compared with that during P1 due to a larger east-west SST gradient and enhanced tropical warming in the Indian Ocean. When the IPO is negative during P2, a wider scope of the wind stress anomalies associated with the IPO could lead to 1) the southward migration of the North Equatorial Current bifurcation latitude (NECBL) by affecting the wind stress curl over the key region where it is near the climatological NECBL and 2) an increase in the interbasin pressure gradient (sea surface height difference) between the western Pacific and the SCS; these two processes strengthen the Kuroshio and weaken the Luzon Strait transport (LST) or SCS throughflow into the SCS. Also, 3) the equatorial Pacific wind anomalies are wide enough to directly weaken the LST in the SCS through the "island rule." These three pathways finally change the oceanic gyre in the SCS and increase the OHC. Our results suggest that the scope of the tropical wind stress is the crucial factor when we consider the relationship between the upper ocean thermal conditions in the SCS and the Pacific variability.
\end{abstract}

\section{Introduction}

The upper-ocean heat content $(\mathrm{OHC})$ is more suitable than sea surface temperature (SST) for monitoring ongoing global warming and climate change (Levitus et al. 2000, 2001; Chen and Tung 2014; von Schuckmann et al. 2014; Nieves et al. 2015; Liu et al. 2016). Therefore, it is important to investigate the $\mathrm{OHC}$ variability on both

\footnotetext{
Supplemental information related to this paper is available at the Journals Online website: https://doi.org/10.1175/JCLI-D-190679.s1.
}

Corresponding author: Dr. Dongxiao Wang, dxwang@scsio.ac.cn global and regional scales. Recent studies have shown that the $\mathrm{OHC}$ and the subsurface temperature in the western North Pacific Ocean have major impacts on tropical cyclone activities and the South China Sea (SCS) summer monsoon (Pun et al. 2007; Feng and Hu 2014; Huang et al. 2015). The SCS, which is part of the western Pacific warm pool, is the largest semi-enclosed marginal sea in the northwest Pacific. Land-sea thermal contrasts between the SCS and the Indo-China Peninsula and southern China play an important role in the climate system of Southeast Asia (Wang et al. 2007; Fang et al. 2009; Roxy and Tanimoto 2012). We need to improve our understanding of the upper ocean thermal conditions in the SCS to provide more evidence for regional climate prediction. 
Observational analyses have shown that the upper ocean thermal conditions in the SCS exhibit abundance of multiple time scales from seasonal to decadal variabilities, which are largely attributable to the East Asian monsoon, El Niño-Southern Oscillation (ENSO), and the interdecadal Pacific oscillation (IPO). The characteristics and mechanisms for the SCS OHC-IPO connection remain relatively unexplored (Xiao et al. 2019).

The upper-layer temperature shows remarkable seasonal variations at the basin scale under monsoonal forcing (Shen and Lau 1995; Chu et al. 1999; Qu 2001; Chen et al. 2003). The surface heat fluxes associated with the monsoon are the major factors controlling sea surface temperature in the SCS, while the ocean dynamic process is the second factor ( Qu 2001). SST in the SCS shows a significant intraseasonal signal during the East Asian monsoon period (Gao and Zhou 2002), which can in turn impact the monsoon variability, and this could make the air-sea interaction in the SCS become more complex during the monsoon period (Roxy and Tanimoto 2012; Wu and Chen 2015).

Interannual variability of the upper-layer temperature in the SCS has been investigated in many studies. He and White (1987) found that the upper 200-m OHC in the SCS increased during the mature phase of the 1982/83 El Niño event. Tomita and Yasunari (1996) noticed that the SST in the SCS was closely linked to the SST in the equatorial central Pacific in wintertime. Ose et al. (1997) analyzed observational data and found that the close relationship between the warm SST anomalies in summertime in the SCS and warm SST anomalies in the previous wintertime in the equatorial central Pacific may be established through the wind fields. After the 1997/98 super El Niño event, many studies have shown that the ENSO could lead by 5 months and affect the SST in the SCS (Klein et al. 1999; Wang et al. 2000). Then, the concept of an "atmospheric bridge" that connects the ENSO and East Asian climate was proposed (Wang 2002; Xie et al. 2003; Liu et al. 2004; C. Wang et al. 2006; Rong et al. 2007). In addition to the atmospheric bridge, the ENSO signal could be transported into the SCS through the Luzon Strait. Qu et al. (2004) found that the Luzon Strait transport (LST) was higher during an El Niño year, and the heat budget results showed that the LST plays a cooling role in modulating the heat balance in the SCS. D. Wang et al. (2006) used the "island rule" to calculate the LST, and noted that the Kuroshio weakened (strengthened), and the LST or the SCS throughflow (SCSTF) became stronger (weaker), which led to negative (positive) OHC anomalies in the SCS (Liu et al. 2012).

Due to limited observational data of the subsurface temperature, the characteristics of the upper thermal structures in the SCS and their mechanisms at the decadal time scale remain relatively unclear, although some studies have revealed the imprint of the Pacific decadal oscillation (PDO) on the LST and sea level in the SCS (Yu and Qu 2013; Cheng et al. 2016). Our recent study showed that the OHC in the SCS exhibits a regime shift during the late 1990s on a decadal time scale, which is attributed to the phase transition of the IPO (Xiao et al. 2019). We noticed that the IPO had a highly negative relationship with the OHC in the SCS during 1990-2010 $(r=-0.86)$ but a very weak negative relationship $(r=-0.15)$ during 1975-89 in Fig. 12 of Xiao et al. (2019). Similar interdecadal changes in the relationship have also been found in other studies. Yu and Qu (2013) revealed that the positive phase of the PDO could enhance the Aleutian low and lead to westerly wind anomalies over the subtropical North Pacific, and then the North Equatorial Current bifurcation latitude (NECBL) shifts northward, resulting in a stronger SCSTF. In their study, they pointed that the LST and the PDO are out of phase during 1980-93, and the causes of these exceptions are unclear. Cheng et al. (2016) investigated the modulation of the PDO index on the sea surface level anomalies (SLA) in the SCS through the Rossby wave propagating from the eastern boundary, and they also found that the PDO and SLA were out of phase during 1980-93, which could not be explained by the wave process. From these studies, the unstable relationship between the PDO and the ocean circulations/thermal revealed by the observations and model simulations could be confirmed. We pointed that the air-sea interaction in the tropical and subtropical Pacific (especially the tropical trade winds) are very important in modulating the OHC in the SCS (Xiao et al. 2019), so we think the IPO is more suitable than the PDO in the study of the OHC decadal variability in the SCS. In this study, we aim to provide a comprehensive view by considering the oceanic and atmospheric processes to explain this interdecadal change in the $\mathrm{OHC}-$ IPO connection.

The remainder of this paper is organized as follows. The data and methods used in this study are introduced in section 2. An enhanced footprint of the IPO on the OHC in the SCS since the 1990s is described in section 3 . The mechanisms associated with the interdecadal change are investigated in section 4. Finally, a summary and discussion are given in section 5 .

\section{Data and methods}

\section{a. Data}

Our previous studies have shown that the Simple Ocean Data Assimilation (SODA, version 2.2.4) reanalysis data 
(Carton and Giese 2008) are good enough to estimate the upper $300 \mathrm{~m}$ of the OHC in the SCS compared with the observations (Xiao et al. 2018, 2019). In this study, the upper-layer temperature, ocean current velocity field, and sea surface height (SSH) are obtained from the SODA reanalysis data. To explore the associated possible mechanisms, the monthly mean SST data are obtained from the Hadley Centre Sea Ice and Sea Surface Temperature dataset (HadISST; Rayner et al. 2003); and the net surface heat flux and its components, surface winds, and sea level pressure are obtained from the Twentieth Century Reanalysis (20CRv2) Project provided by the National Oceanic and Atmospheric Administration (NOAA) (Compo et al. 2011). To further verify the results of the SSH in the SODA reanalysis data and ocean model, the observations from the French Archiving, Validation and Interpretation of Satellite Oceanographic Data (AVISO) project are used in this study (Ducet et al. 2000). We take 1960-2010 as our target period in this study. The annual-mean data are calculated from monthly data, and the anomaly is obtained by subtracting the climatology.

\section{b. Upper-layer ocean heat budget}

The heat budget for the upper $300 \mathrm{~m}$ of the $\mathrm{OHC}$ is written following Zhai and Sheldon (2012):

$$
\underbrace{\rho c_{p} \int_{-300}^{0} \frac{\partial}{\partial t} T d z}_{\text {OHC change }}=\underbrace{Q_{\text {net }}}_{\text {heat flux }}-\underbrace{\rho c_{p} \int_{-300}^{0} \nabla \cdot(\mathbf{V} T) d z}_{\text {advection }}+R,
$$

where $T$ is ocean temperature, $Q_{\text {net }}$ is the net surface heat flux, and $\mathbf{V}$ is a three-dimensional velocity vector. In this study, $\rho$ is the reference density of seawater $\left(1027 \mathrm{~kg} \mathrm{~m}^{-3}\right)$ and $c_{p}$ is the specific heat capacity (4007 $\left.\mathrm{J}{ }^{\circ} \mathrm{C}^{-1} \mathrm{~kg}^{-1}\right)$. The terms from the left-hand side of Eq. (1) correspond to terms for $\mathrm{OHC}$ tendency or $\mathrm{OHC}$ change (HCC), heat flux, ocean advection, and a residual term. The residual term includes the contribution of horizontal and vertical diffusivities to the HCC, which are negligible in the SCS on a decadal time scale ( $\mathrm{Li}$ et al. 1999; Qu 2000). In fact, the influence of anomalous Ekman transport and eddies on the advection term could also be negligible in comparison with that of the geostrophic current in the SCS; for example, the contribution of the eddies is one order smaller $\left(\sim 10^{13} \mathrm{~W}\right)$. But in this study, we will not discuss them individually.

\section{c. Island rule}

The Sverdrup theory depicts a theoretical relationship between surface wind stress and vertically integrated meridional transport in the open ocean. The island rule was put forward by Godfrey (1989) to establish a relationship between the transport around a midocean island and wind stress integration along the western boundary of the island and the boundary between the island and the eastern continent based on a steady and frictionless Sverdrup theory. The island rule was strictly deduced and modified by Wajsowicz (1993) and applied to estimate the net transport of the Indonesian Throughflow (ITF).

D. Wang et al. (2006) calculated the LST based on the island rule. The equation is written by an integration of wind stress along the closed pathway $A B C D$ (see Fig. 6d):

$$
\mathrm{LST}=\oint_{\mathrm{ABCD}} \tau^{l} d l /\left[\rho_{0}\left(f_{D}-f_{A}\right)\right],
$$

where $\tau^{l}$ is the wind stress along the closed pathway, $A B$ and $C D$ are the pathways along $4.75^{\circ}$ and $18.75^{\circ} \mathrm{N}$, respectively, $f_{A}$ and $f_{D}$ are the Coriolis parameters at the latitudes of $4.75^{\circ}$ and $18.75^{\circ} \mathrm{N}$, respectively, and $\rho_{0}$ is the density of seawater $\left(1027 \mathrm{~kg} \mathrm{~m}^{-3}\right)$.

\section{d. The baroclinic Rossby wave model}

To investigate the role of the wind stress forcing and Rossby waves in the $\mathrm{OHC}$ in the SCS associated with the IPO, we adopt a simplified 1.5-layer reduced-gravity model under the longwave approximation (baroclinic Rossby wave model) in this study. Following Qiu (2002), the equation is written as follows:

$$
\frac{\partial h}{\partial t}-C_{R} \frac{\partial h}{\partial x}=-\frac{g^{\prime} \nabla \times \tau}{\rho_{0} g f}-\varepsilon h,
$$

where $h$ represents the SSH anomalies, $C_{R}$ is the phase speed of long baroclinic Rossby waves (Chelton and Schlax 1996), $g$ and $g^{\prime}$ are the gravitational constant and reduced-gravity, respectively, $\tau$ is the wind stress vector, $\rho_{0}$ is the reference density for seawater, $f$ is the Coriolis parameter, and $\varepsilon$ is the Newtonian dissipation rate. If the influence of the wind forcing on the $\mathrm{SSH}$ anomaly signal was considered, by integrating Eq. (3) from the eastern to western boundary, we can obtain the solution as follows:

$$
\begin{aligned}
h(x, y, t)= & \frac{1}{\rho_{0} g f} \int_{x_{e}}^{x} \frac{g^{\prime}}{C_{R}} \nabla \times \tau\left(x^{\prime}, y, t+\frac{x-x_{e}}{C_{R}}\right) \\
& \times \exp \left\{\left[\frac{\varepsilon}{C_{R}}\left(x-x_{e}\right)\right]\right\} d x^{\prime} .
\end{aligned}
$$

The model was configured to the Pacific Ocean $\left(20^{\circ} \mathrm{S}-\right.$ $40^{\circ} \mathrm{N}, 90^{\circ} \mathrm{E}-70^{\circ} \mathrm{W}$ ) with a horizontal resolution of $0.25^{\circ} \times$ $0.25^{\circ}$. The control run is forced by the monthly wind from the 20CRv2 data, which covers the period 1960-2010 and 
(a) EOF1+WindClim $35 \%$

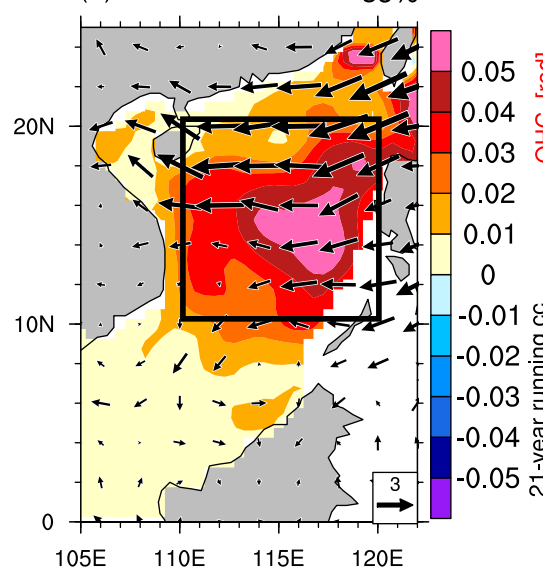

(b)

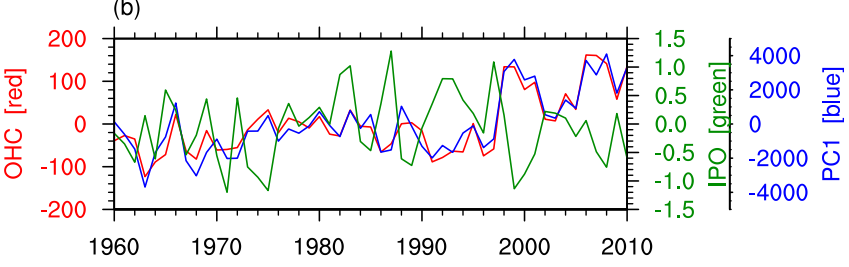

FIG. 1. (a) The EOF1 mode of the annual-mean OHC anomalies during 1960-2010; the black box indicates the region over the north-central $\operatorname{SCS}\left(10^{\circ}-20^{\circ} \mathrm{N}, 110^{\circ}-120^{\circ} \mathrm{E}\right)$ and the vectors are the climatologic surface wind fields during 1960-2010. (b) Corresponding PC1 (blue line), IPO index (green line), and box-averaged OHC anomalies over the north-central SCS (red line). (c) Time series of 21-yr running correlation coefficient between the IPO index and the box-averaged $\mathrm{OHC}$ anomalies.

is the same forcing as that used in producing the SODA reanalysis data. We set $\rho_{0}=1027 \mathrm{~kg} \mathrm{~m}^{-3}, g^{\prime}=0.03 \mathrm{~m} \mathrm{~s}^{-2}$ (Chen and $\mathrm{Wu} 2011$ ), and $\varepsilon=1 / 3 \mathrm{yr}^{-1}$ (Wang et al. 2015). The configurations of the sensitivity experiments will be described in the relevant sections.

\section{e. The choice of indices}

1) The interdecadal Pacific oscillation index is based on the difference between the SST anomalies averaged over the northwest (region $1 ; 25^{\circ}-45^{\circ} \mathrm{N}, 140^{\circ} \mathrm{E}-$ $145^{\circ} \mathrm{W}$ ) and the central equatorial Pacific (region 2; $10^{\circ} \mathrm{S}-10^{\circ} \mathrm{N}, 170^{\circ} \mathrm{E}-90^{\circ} \mathrm{W}$ ) and the southwest Pacific (region $3 ; 50^{\circ}-15^{\circ} \mathrm{S}, 150^{\circ} \mathrm{E}-160^{\circ} \mathrm{W}$ ) (Henley et al. 2015); the unfiltered IPO index is computed as follows:

$$
\mathrm{IPO}=\mathrm{SSTa}_{2}-\frac{\left(\mathrm{SSTa}_{1}+\mathrm{SSTa}_{3}\right)}{2} .
$$

2) The averaged upper $300-\mathrm{m}$ NECBL is defined as the zero of the meridional velocity within a $2^{\circ}$ longitude band off the Philippine coast (Chen and Wu 2012; Xiao et al. 2018). According to Chen and Wu (2012) and $\mathrm{Hu}$ et al. (2015), the NEC is mainly controlled by the geostrophic westward currents below a very thin Ekman layer ( $\sim 36 \mathrm{~m})$. So, the averaged upper 300-m NECBL could also be defined by the geostrophic currents, and this definition will be used in the model result (section $4 b$ ). The difference between these two definitions could be neglected when we focus on the upper 300-m layer.
3) The upper 300-m Luzon Strait transport (LST) and Kuroshio Current transport (KC) are defined as the transport across the $120.25^{\circ} \mathrm{E}$ transect between $18.25^{\circ}$ and $22.25^{\circ} \mathrm{N}$ and the transport across the $18.25^{\circ} \mathrm{N}$ transect between $122.25^{\circ}$ and $123.75^{\circ} \mathrm{E}$, respectively (Xiao et al. 2018).

\section{Enhanced OHC-IPO connection since the 1990s}

\section{a. Spatiotemporal characteristics}

To examine the spatiotemporal characteristics of the $\mathrm{OHC}$ in the SCS, an empirical orthogonal function (EOF) analysis is applied to the annual-mean $\mathrm{OHC}$ anomalies over the region of $0^{\circ}-25^{\circ} \mathrm{N}, 105^{\circ}-122^{\circ} \mathrm{E}$. The results of the first mode (EOF1) and corresponding principal component (PC1) are shown in Figs. 1a and 1b. The EOF1 mode is characterized by positive OHC anomalies over the entire basin, which explains approximately $35 \%$ of the total variances and is distinguished from other modes by North's test (North et al. 1982). The center of the positive OHC anomalies is located at the central SCS, and the averaged OHC over the region of $10^{\circ}-20^{\circ} \mathrm{N}, 110^{\circ}-120^{\circ} \mathrm{E}$ is highly correlated with the PC1 $(r=0.95)$; thus, the OHC in the SCS will be referred to as the box-averaged $\mathrm{OHC}$ in the next discussion. A 21-yr running correlation analysis was performed between the OHC in the SCS and the IPO index, and an enhanced footprint of the IPO on the OHC is seen in the SCS since the 1990s (Fig. 1c). The whole period could be classified into two subperiods: a period of weak relationship (1960-80, hereafter P1; correlation 

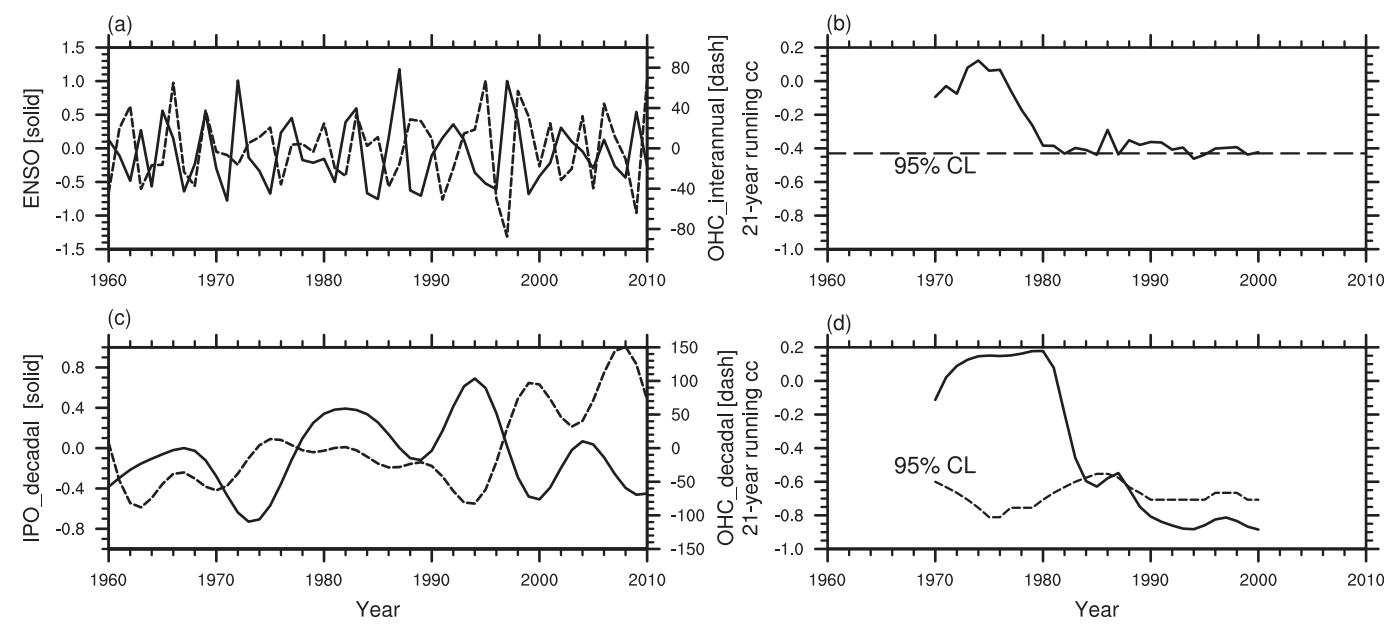

FIG. 2. (a) Time series of the IPO index and the OHC in Fig. 1b, but after 2-7-yr bandpass filtered. (b) Time series of 21-yr running correlation coefficient in (a). (c),(d) As in (a),(b), but for 7-yr low-pass filtered results.

coefficient is -0.03 ) and a period of strong relationship (1990-2010, hereafter P2; correlation coefficient is -0.71); the period of $1980-89$ is transitional. The vertical structure of the upper-ocean temperature associated with the IPO is shown in Fig. S1 in the online supplemental material. The climatological mixed-layer depth (MLD) in the SCS is only approximately $40 \mathrm{~m}$ (Liu et al. 2014; Zeng et al. 2016). The MLD temperature has weak correlations with the IPO during the whole period and two subperiods, but the subsurface temperature between 50 and $300 \mathrm{~m}$ has strong correlations with the IPO during 1990-2010, especially at depths between 100 and $150 \mathrm{~m}$. This contrasting change in the surface and subsurface water in the SCS has been discussed by Xiao et al. (2019). The SST or MLD temperature in the SCS is out of phase with the IPO but in phase with global warming due to the sensitivity to the surface heat flux changes induced by global warming. The spatial distributions of correlation coefficients between the $\mathrm{OHC}$ in the SCS and IPO during P1 and P2 are shown in Fig. S2. A strong positive relationship could be found in the central SCS during P2, especially along Luzon Island.

The unfiltered IPO index and OHC in Figs. $1 b$ and $1 c$ contain two signals on interannual and decadal time scales. So, which time scale causes the enhanced relationship between these two variables? A 2-7-yr bandpass filter and a 7-yr low-pass filter are applied to the unfiltered IPO index and the OHC to highlight the contributions of the interannual and decadal variabilities (Fig. 2). The interannual component is actually the ENSO-like signal as shown in Fig. 2a, and the 21-yr running correlation coefficient shows a weak linkage on the interannual time scale (Fig. 2b). This is because the impact of ENSO events on the OHC in the SCS has strong seasonal variations that induce negative $\mathrm{OHC}$ anomalies during mature phases (Yan et al. 2010; Liu et al. 2012). The decadal component is the IPO as shown in Fig. 2c, and the result of a 21-yr running correlation coefficient in Fig. 2d is similar to the unfiltered result in Fig. 1c. The corresponding significance was recalculated based on the Student's $t$ test after adjusting the effective number of degrees of freedom $\left(N^{\text {eff }}\right)$ following Bretherton et al. (1999):

$$
\frac{1}{N^{\mathrm{eff}}} \approx \frac{1}{N}+\frac{2}{N} \sum_{j-1}^{N} \frac{N-j}{N} \rho_{X X}(j) \rho_{Y Y}(j),
$$

where $N$ is the sample size and $\rho_{\mathrm{XX}}(j)$ and $\rho_{\mathrm{YY}}(j)$ are the autocorrelations of the of two sampled time series $X$ and $Y$ at time lag $j$, respectively. These results illustrate that the enhanced footprint of the Pacific variability on the OHC in the SCS since the 1990s is attributed to its decadal component (IPO).

To detect the mechanisms for interdecadal changes in the OHC-IPO connection, we need to understand what process controls the $\mathrm{OHC}$ in the SCS during $\mathrm{P} 1$ and $\mathrm{P} 2$. Figure 3 shows the different SSTs and wind patterns related to the $\mathrm{OHC}$ in the SCS during $\mathrm{P} 1$ and $\mathrm{P} 2$. The SST shows a dipole mode during P1: the positive SST anomalies are located in the SCS and Philippine Seas, and the negative anomalies are located in the central northern Pacific Ocean (Fig. 3a). The SST pattern shows that negative anomalies are located in the equatorial Pacific, and positive anomalies are located in the northwestern Pacific, which shows a typical IPO pattern during P2 (Fig. 3b). The wind patterns are also completely different. An anomalous anticyclonic circulation is located over the northwestern Pacific as a response to the SST during P1 (Fig. 3c), while easterly wind anomalies over the tropical Pacific are observed 

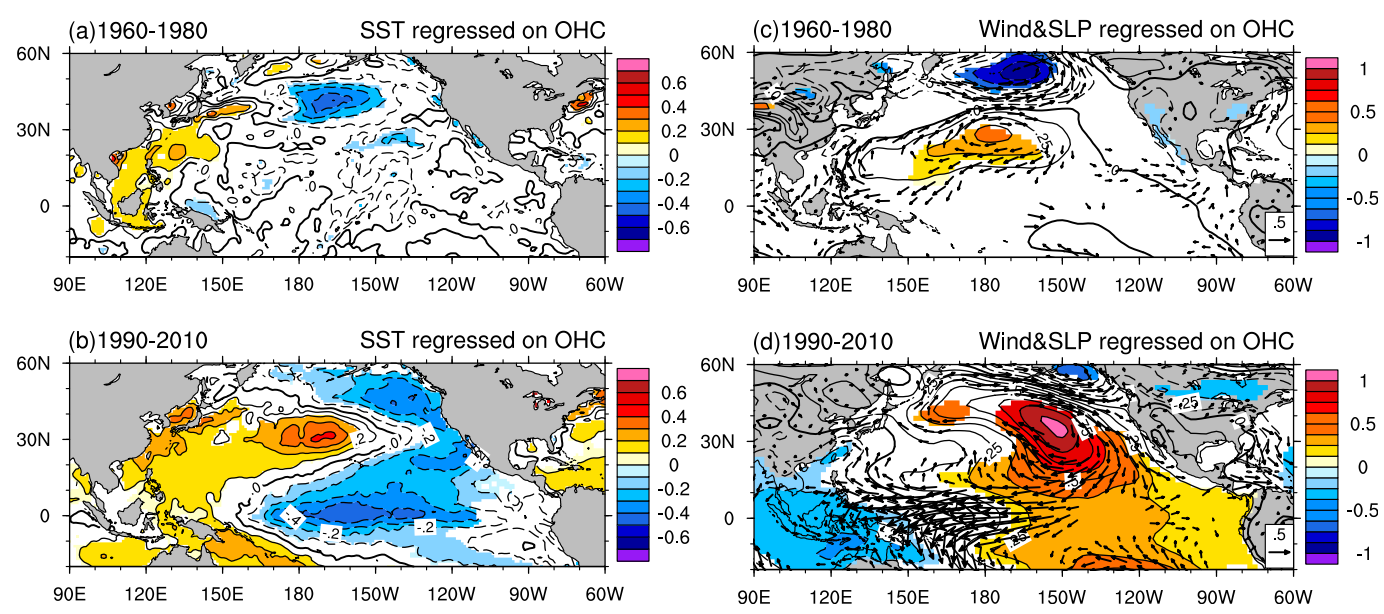

FIG. 3. (a) The regression coefficients of the SST anomalies onto the OHC anomalies over the north-central SCS during 1960-80. (b) As in (a), but for the period of 1990-2010. (c) The regression coefficients of the surface wind vector and the SLP anomalies onto the OHC anomalies over the north-central SCS during 1960-80. (d) As in (c), but for the period of 1990-2010. Shaded areas and vectors are only shown for the results exceeding the $95 \%$ confidence level (Student's $t$ test).

during P2 (Fig. 3d). These results indicate that different forcings control the $\mathrm{OHC}$ in the SCS during different periods.

\section{b. Heat budget}

To examine the major factor controlling the $\mathrm{OHC}$ in the SCS during P1 and P2, Eq. (1) is applied over the major region in Fig. 1a. We compare the sum of the advection and the net surface heat flux terms with the HCC (Fig. 4a) and the contribution percentages of the advection and the net surface heat flux terms (Fig. 4b). The correlation coefficients between the HCC and the advection term is $0.55^{*}$ [the asterisk $\left({ }^{*}\right)$ means the correlation coefficient exceeds the $99 \%$ confidence level], while between the HCC and the net surface heat flux term is only 0.29 during the whole period. There are only 15 years in which the contribution of the surface heat flux term exceeds the advection term during 1960-2010 (Fig. 4b). Therefore, the advection induced by the oceanic gyre is the major factor controlling the HCC during the entire period, which is consistent with the findings of our previous study (Xiao et al. 2019). When we focus on the two subperiods, the situation seems to be different. Although the advection term is the main factor $(r=$ $0.62 *)$, the net surface heat flux term could not be neglected $\left[r=0.46^{\#}\right.$; the superscript hash sign $\left({ }^{\#}\right)$ means the correlation coefficient exceeds the $95 \%$ confidence level] during P1. The correlation coefficient between the HCC and the advection term increased to $0.68^{*}$, while the correlation coefficient between the HCC and the net surface heat flux term decreased to 0.34 during $\mathrm{P} 2$. The results indicate that the advection term associated with the anomalous oceanic gyre is likely the most important factor in the enhanced relationship between the OHC in the SCS and IPO since the 1990s.

Figures $5 \mathrm{a}$ and $5 \mathrm{~b}$ show the regressions of the upper 300-m average currents onto the averaged OHC anomalies during P1 and P2. Anomalous anticyclonic currents are tied to the $\mathrm{OHC}$ in the north-central SCS, but a stronger circulation exists during P2. The positive wind

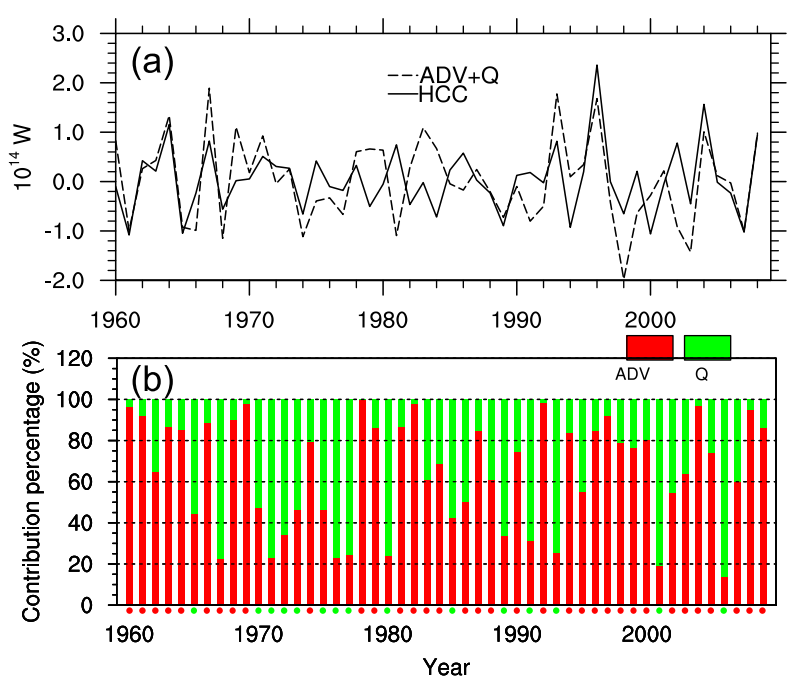

FIG. 4. (a) The heat budget results. Solid line and dashed line indicate the $\mathrm{OHC}$ change (HCC) and the sum of the advection and the net surface heat flux terms $(\mathrm{ADV}+Q)$. (b) The contribution percentages of the advection and the net surface heat flux terms, red dots indicate the contribution percentage of the ADV term exceed $50 \%$ and green dots indicate the contribution percentage of the $Q$ term exceed $50 \%$. 


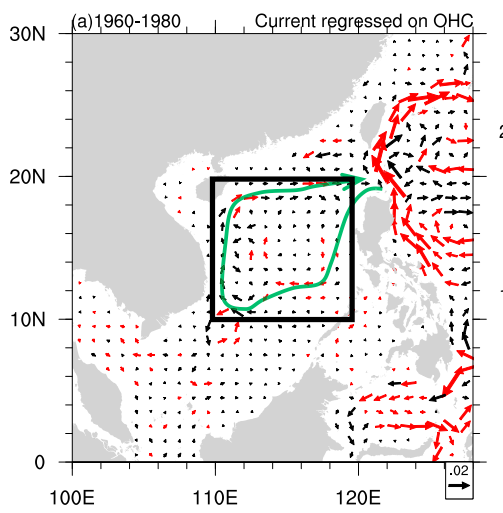

(c)1960-1980 WSC regressed on OHC

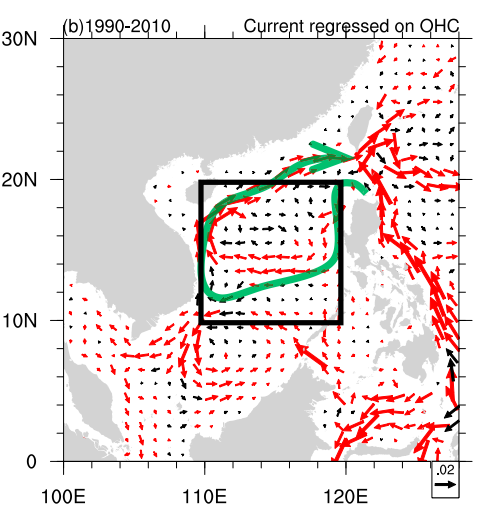

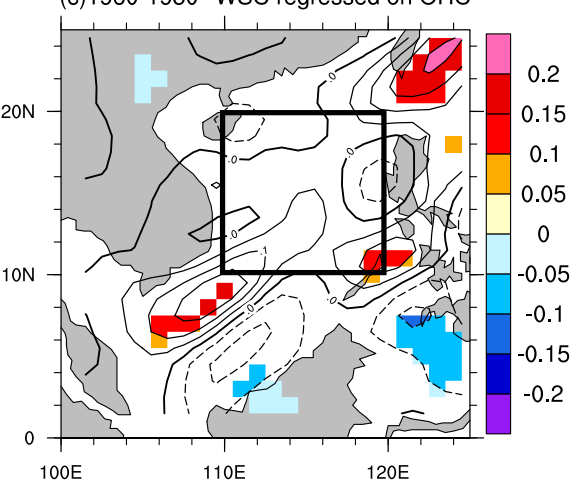

(d)1990-2010 WSC regressed on OHC (e)1960-1980 Qnet regressed on HCC

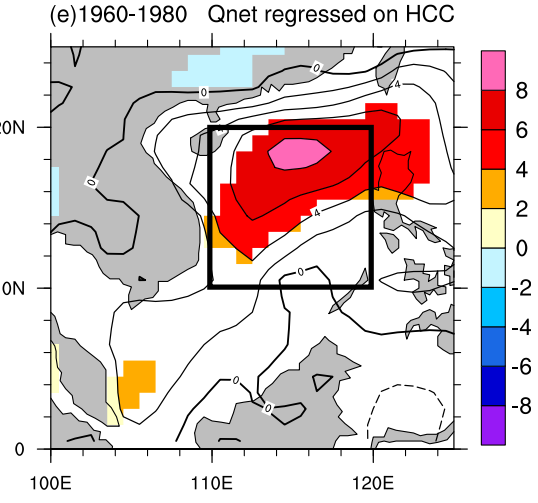

(f) 1990-2010 Qnet regressed on HCC

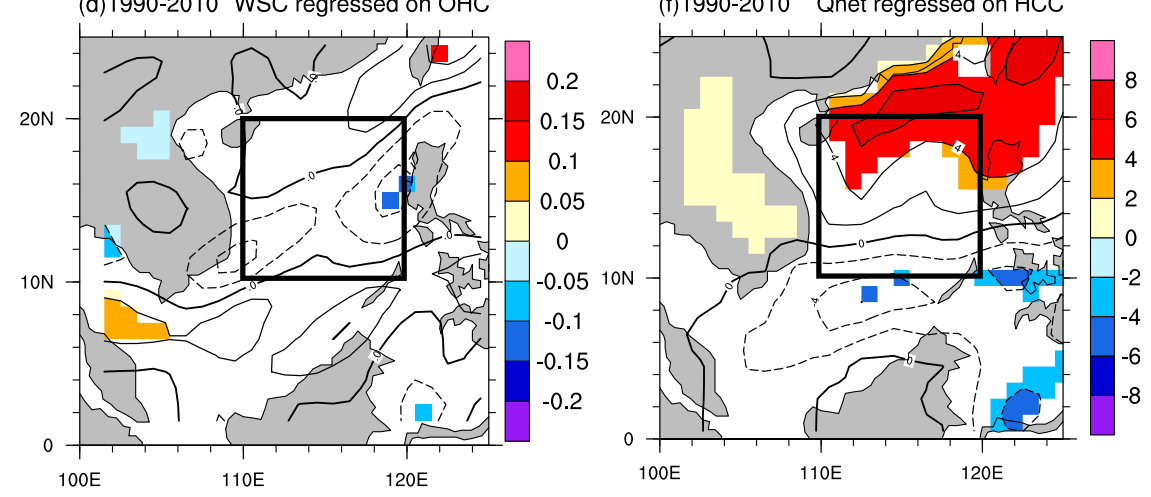

FIG. 5. (a) The regression coefficients of the upper 300-m average current anomalies onto the OHC anomalies over the north-central SCS during 1960-80. (c) As in (a), but for the wind stress curl anomalies. (e) The regression coefficients of the net surface heat flux anomalies onto the HCC over the north-central SCS during 1960-80. (b),(d),(f) As in (a),(c),(e), but for the period of 1990-2010. Shaded areas and red vectors are only shown for the results exceeding the $95 \%$ confidence level (Student's $t$ test), black box is as in Fig. 1, and green vectors indicate the anomalous anticyclonic gyre in the SCS.

stress curl anomalies associated with the OHC could not explain the anomalous anticyclonic currents in the northcentral SCS during P1 (Fig. 5c), and the negative wind stress curl anomalies in the central SCS could only explain parts of the anomalous anticyclonic currents during P2 (Fig. 5d). It seems that the local wind stress curl anomalies could not induce the anomalous anticyclonic current patterns, but the wind speed anomalies could influence the net surface heat flux in the SCS. From Figs. 5e and 5f, we find that the net surface heat flux into the northern central SCS plays an important role in changing the HCC, which means that the positive net surface heat flux into the SCS could increase the OHC. The location of the net surface heat flux is more northward, and the strength of the net surface heat flux is weaker during $\mathrm{P} 2$, which is consistent with the contribution of the net surface heat flux term on the HCC decreases during P2. Then we analyzed the relative contributions of the four components of the net surface heat flux: latent heat flux (LHF), sensible heat flux, shortwave radiation, and longwave radiation (figures not shown). LHF appears to be the major component of the total net surface heat flux during the entire period. Anomalous wind directions in the SCS play a key role in modulating the LHF. Following Xie et al. (2010), we can decompose LHF into a Newton damping and atmospheric forcing (notably wind speed),

$$
\mathrm{LHF}=\mathrm{LHFn}+\mathrm{LHFa} .
$$

If the relative humidity is a constant and the surface airsea temperature difference is neglected over the SCS, the atmospheric forcing could be obtained:

$$
\mathrm{LHFa} \approx \mathrm{LHFw}=\frac{\partial \mathrm{LHF}}{\partial W} W^{\prime}=\frac{\overline{\mathrm{LHF}}}{\bar{W}} W^{\prime},
$$

where $W$ is the scalar wind speed, overbar and the prime denote the climatological mean and the anomaly, respectively.

The results show that the contributions of the wind speed and Newton damping to the LHF are approximately $70 \%$ and $30 \%$ during P1, and approximately $60 \%$ and $40 \%$ during P2 (Fig. S3). The LHF induced by the wind speed is the much more important than the Newton damping over the SCS. Back to Fig. 3c, the 

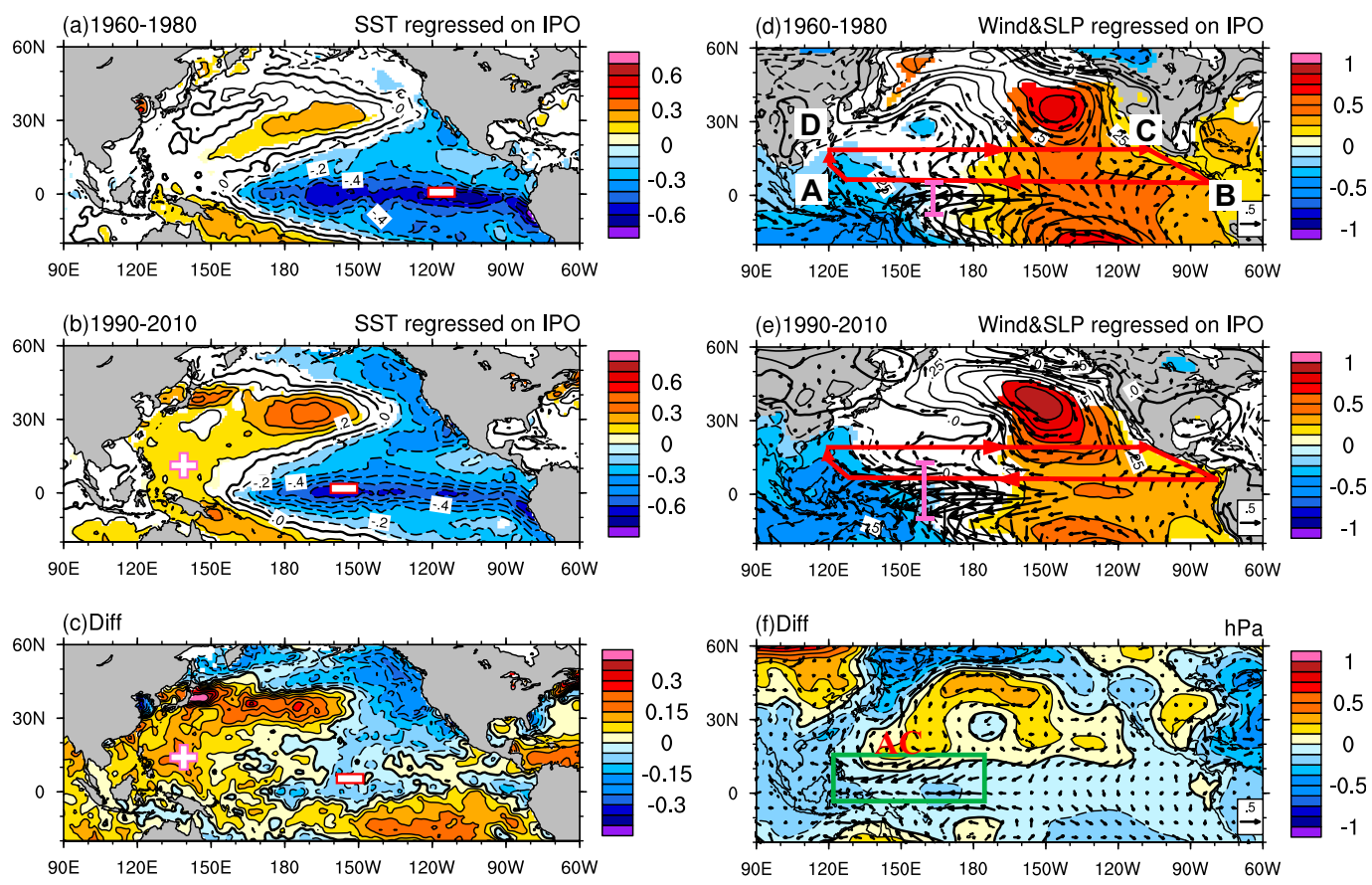

FIG. 6. (a) The regression coefficients of the SST anomalies onto the IPO index (multiplied by -1) during 196080 (units: ${ }^{\circ} \mathrm{C}$ ). (d) As in (a), but for the surface wind vectors (units: $\mathrm{m} \mathrm{s}^{-1}$ ) and the SLP anomalies (units: hPa). (b),(e) As in (a),(d), but for the period of 1990-2010. Shaded areas and red vectors in (a), (b), (d), and (e) are only shown for the results exceeding the $95 \%$ confidence level (Student's $t$ test). Also shown are (c) the difference between (b) and (a), and (f) the difference between (e) and (d). $A B C D$ is the integrational pathway in the island rule; a magenta line segment indicates the width of the equatorial Pacific winds.

southerly anomalous winds could decrease the climatological wind speed (northeasterly; see Fig. 1a) to decrease the air-sea exchange and increase the OHC in the SCS during P1, especially in the central SCS. From Fig. 3d, the easterly anomalous winds could not decrease as much as the climatological wind speed in the central SCS during P2 than P1, so the impact of the surface heat flux on the $\mathrm{OHC}$ became weaker compared with that during P1.

\section{Interpretations of the interdecadal change in the OHC-IPO connection}

\section{a. Different characteristics of the IPO during P1 and $P 2$}

How could the IPO connect (disconnect) with the $\mathrm{OHC}$ in the SCS during P2 (P1)? First, we need to check the air-sea variables related to the IPO during these two periods. Figures $6 \mathrm{a}$ and $6 \mathrm{~b}$ show the regressions of the SST anomalies onto the IPO (multiplied by -1 ) and are compared with Fig. 3 during P1 and P2. Both figures depict negative SST anomalies in the central equatorial Pacific and positive anomalies in the northwest Pacific. The anomalous east-west SST gradient could be found in their differences (Fig. 6c). For the atmospheric variables, we find that the patterns of sea level pressure (SLP) and wind anomalies are similar during P1 and P2. A westward shift in the tropical Walker circulation is observed because the east-west SST gradient is larger during P2 (Fig. 6e; Williams and Funk 2011; Ma and Zhou 2016). Usually, the tropical Walker circulation could be measured by the zonal SLP gradient between the western and eastern Pacific because of the strong dynamical linkage between the zonal SLP gradient and the zonal wind (Clarke and Lebedev 1996). However, use of the zonal SLP gradient in this study has some limitations. First, the theory could be established only near the equator within the boundary layer (Xiang et al. 2014). Second, the zonal SLP gradient could not give the range of the zonal wind anomalies quantitatively. We can see the easterly wind anomalies are stronger and wider (over approximately $8^{\circ} \mathrm{S}-12^{\circ} \mathrm{N}, 130^{\circ} \mathrm{E}-150^{\circ} \mathrm{W}$ ) during $\mathrm{P} 2$ but weaker and narrower (over approximately $6^{\circ} \mathrm{S}-6^{\circ} \mathrm{N}, 150^{\circ} \mathrm{E}-150^{\circ} \mathrm{W}$ ) during P1 (Fig. S4). The differences in surface winds between $\mathrm{P} 2$ and $\mathrm{P} 1$ show an anticyclonic anomaly over the northwest Pacific with enhanced easterly winds over the western tropical Pacific (Fig. 6f), which is consistent with the previous study that the trade winds over the tropical Pacific are enhanced during recent 
decades (England et al. 2014). One important cause of the enhanced trade wind could be attributed to the enhanced tropical warming in the Indian Ocean relative to the Pacific Ocean through modulation of the atmospheric Walker circulation (Luo et al. 2012; Han et al. 2014; Zhang 2016; Zhang et al. 2018; Dong and McPhaden 2017). The ocean-atmosphere positive feedback between the east-west SST gradient and trade wind in the Pacific will subsequently amplify the enhanced trade wind changes in the Pacific. We average the zonal wind speed over the western tropical Pacific (green box in Fig. 6f), and the result shows a similar relationship between the OHC in the SCS and IPO (Fig. S5). The zonal winds over the western tropical Pacific may be a key factor for connecting the OHC and IPO. We apply a partial correlation analysis between the SST and the regional mean $\mathrm{OHC}$ in the SCS after removing the influence of the zonal winds over the tropical Pacific (Fig. 7). The results show that the spatial distributions of the correlation coefficients (Fig. 7a) and Fig. 3a are very similar during $\mathrm{P} 1$, while the spatial distributions of the correlation coefficients (Fig. 7b) and Fig. 3b are completely different during $\mathrm{P} 2$. The differences between Figs. $7 \mathrm{~b}$ and $3 \mathrm{~b}$ indicate the importance of the zonal winds over the tropical Pacific in connecting the $\mathrm{OHC}$ and IPO during P2.

Section 3 shows that the advection term induced by the anomalous oceanic gyre is the most important factor for controlling the $\mathrm{OHC}$ in the SCS, especially during P2. Previous studies by D. Wang et al. (2006) and Qu et al. (2004) indicate that there are two pathways connecting the SCS and external forcings: one pathway is that the southward/northward shift in the NECBL affects the LST, and the other pathway is that the tropical zonal wind affects the LST through the island rule. Then, we will check these pathways individually.

\section{b. Associated current systems}

The NEC bifurcates when it encounters the Philippine coast, feeding the KC. According to the linear Sverdrup theory, the bifurcation latitude is determined by the line of zero wind stress curl (Chen and Wu 2011). We have shown that the zonal winds over the western tropical Pacific may be a key factor in connecting the $\mathrm{OHC}$ and IPO. To better illustrate this connection, the baroclinic Rossby wave model is used. We compare the $\mathrm{SSH}$ anomalies observed and simulated in the $12^{\circ}-14^{\circ} \mathrm{N}$ band across the Pacific (Fig. S6), and the results show that the model could capture the SSH anomaly signal very well in the control run.

Figures $8 \mathrm{a}$ and $8 \mathrm{~b}$ show the time series of the IPO and the NECBL in the SODA data and the 21-yr running correlation coefficient between these two variables. We (a)1960-1980 Pcorr(SST\&SCS OHC,zonal wind)

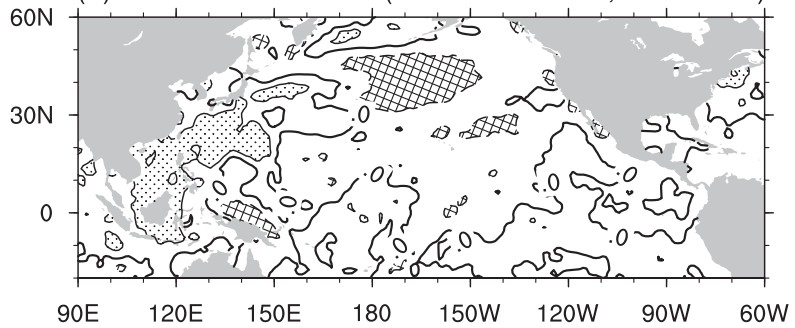

(b) 1990-2010 Pcorr(SST\&SCS OHC,zonal wind)

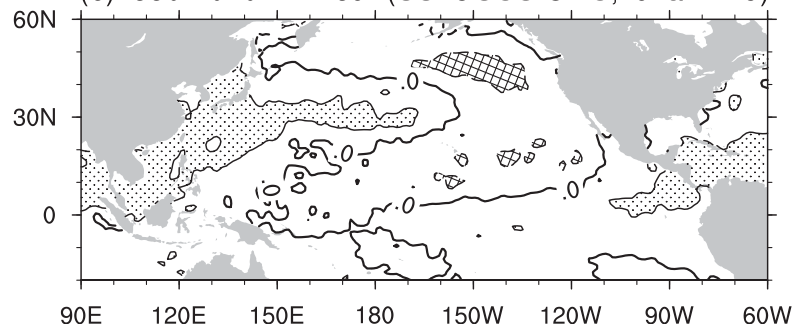

FIG. 7. (a) The partial correlation coefficients between the SST and the $\mathrm{OHC}$ anomalies over the north-central SCS after removing the influence of the zonal wind over the tropical Pacific during 1960-80. (b) As in (a), but for the period of 1990-2010. Shading area indicates the regression coefficients exceed the $95 \%$ confidence level based on the Student's $t$ test.

find that the relationship between the IPO and the NECBL becomes closer with time, but the changepoint is earlier than the 1990s. The model results are shown in Figs. $8 \mathrm{c}$ and $8 \mathrm{~d}$. The NECBL in the model is defined as the position where the mean meridional geostrophic current induced from SSH within $2^{\circ}$ off the band off the Philippine coast is zero (Chen and $\mathrm{Wu}$ 2012). Although the modeled NECBL has some discrepancies compared with the SODA result $(r=$ $\left.0.58^{*}\right)$ and the changepoint is later than the observations, the enhanced relationship could also be captured from the simple model. According to previous studies, the NECBL can be estimated by the mean wind stress curl anomalies over the key region around the climatological NECBL (Qiu and Lukas 1996; Qiu and Chen 2010; Chen and Wu 2012; Wang et al. 2014, 2019). The wind stress curl anomalies associated with the IPO during $\mathrm{P} 1$ and $\mathrm{P} 2$ are shown in Fig. 9. According to previous studies, we define $10^{\circ}-14^{\circ} \mathrm{N}$, $140^{\circ}-170^{\circ} \mathrm{E}$ as the key region (red box in Fig. 9), and we verify the relationship between the box-averaged wind stress curl and NECBL $(r=0.54 *)$, which indicates that the mean wind stress curl anomalies over the key region could estimate the NECBL very well. Therefore, the reason why the IPO has a more significant impact on the NECBL during $\mathrm{P} 2$ is that the associated wind stress curl anomalies are wider enough to cover the key region that affects the NECBL movement (Fig. 9). 

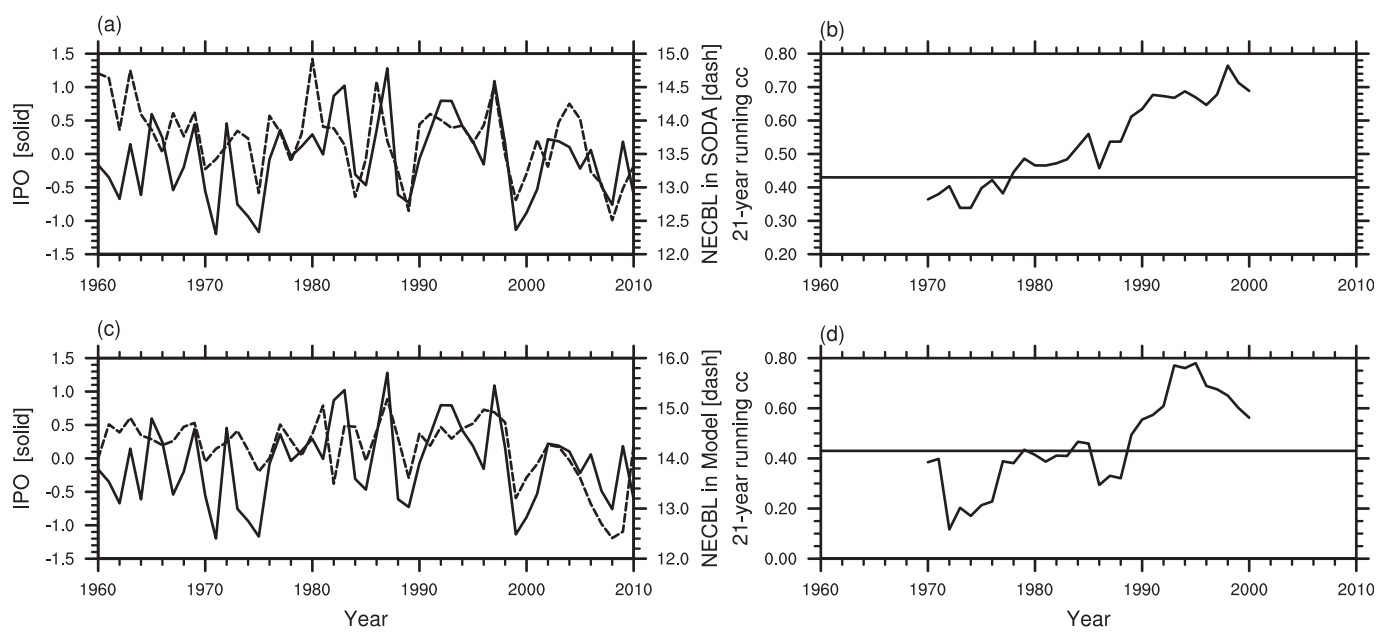

FIG. 8. (a) Solid line and dashed line indicate the IPO index (units: ${ }^{\circ} \mathrm{C}$ ) and the NECBL in the SODA reanalysis (units: ${ }^{\circ} \mathrm{N}$ ). (b) Time series of 21-yr running correlation coefficient between the IPO index and the NECBL in the SODA reanalysis. (c),(d) As in (a),(b), but for the IPO index and the NECBL in the baroclinic Rossby wave model simulation.

Then, we compare the relationship between the $\mathrm{KC}$ and IPO, as well as the LST and IPO (Fig. 10). Both the $\mathrm{KC}$ and the LST show similar enhanced relationships with the IPO. These results are consistent with a previous study ( $\mathrm{Hu}$ et al. 2015) that found that southerly bifurcation of the NEC enhanced the $\mathrm{KC}$, which weakened the SCSTF or LST in the SCS. Using a single-layer depth-averaged approach, Sheremet (2001) investigated a western boundary current encountering a gap in a ridge. When the boundary current decelerates, the meridional advection of potential vorticity cannot overcome the $\beta$ effect, making more water pass through the gap. The situation is reversed when the boundary current accelerates. This behavior is well known as the "teapot effect." According to the teapot effect theory, an enhanced KC could weaken the Kuroshio intrusion into the northern SCS, which further induces anomalous anticyclonic currents (Xiao et al. 2018).

Except for the NECBL, the pressure gradient between the western Pacific and the SCS is another factor that modulates the $\mathrm{KC}$ according to geostrophic theory (Song 2006). Before this analysis, we first compare the LST in the SODA reanalysis data and the average zonal geostrophic current induced by the $\mathrm{SSH}$ difference across the Luzon Strait based on the model simulation (Fig. S7). The correlation coefficient is 0.55 and exceeds the $99 \%$ confidence level based on the Student's $t$ test. This result indicates that the geostrophic relation could be well simulated in the baroclinic Rossby wave model.

In this study, we define the pressure gradient as the $\mathrm{SSH}$ difference between the western Pacific $\left(0^{\circ}-30^{\circ} \mathrm{N}, 122^{\circ}-\right.$ $\left.140^{\circ} \mathrm{E}\right)$ and the $\operatorname{SCS}\left(0^{\circ}-24^{\circ} \mathrm{N}, 105^{\circ}-120^{\circ} \mathrm{E}\right)$. Figure $11 \mathrm{a}$ shows the SSH difference between the western Pacific and the SCS (climatological SSH has been removed) that is obtained from the AVISO and SODA reanalysis, and the SSH difference in the SODA reanalysis is good enough to compare with the observation. Then, we provide the time series of the SSH difference in the SODA reanalysis and the LST (Fig. 11b). The positive correlation coefficient indicates that when the SSH difference between the western Pacific and the SCS increases, the intensity of the KC weakens, and the LST is stronger than normal. The 21-yr running correlation coefficient between these two variables shows that this relationship is significant only after the 1990s (Fig. 11c). A similar interdecadal change could also be obtained from the baroclinic Rossby wave model (Figs. 11d-f), although the bias of the seasonal cycle in the modeled SSH difference is larger than that of the observation.

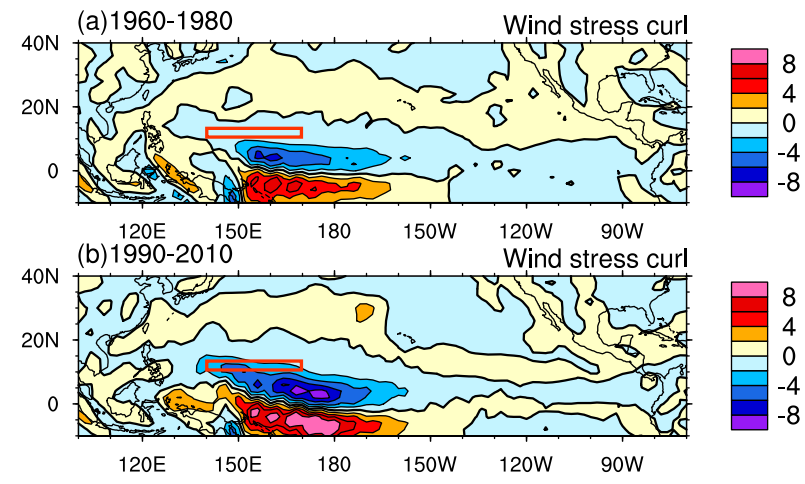

FIG. 9. (a) The wind stress curl anomalies are calculated from Fig. $6 \mathrm{~d}$; the red rectangle indicates the key region $\left(10^{\circ}-14^{\circ} \mathrm{N}, 140^{\circ}-\right.$ $170^{\circ} \mathrm{E}$ ) around the climatological NECBL. (b) As in (a), but for the result from Fig. 6e. 
(a)
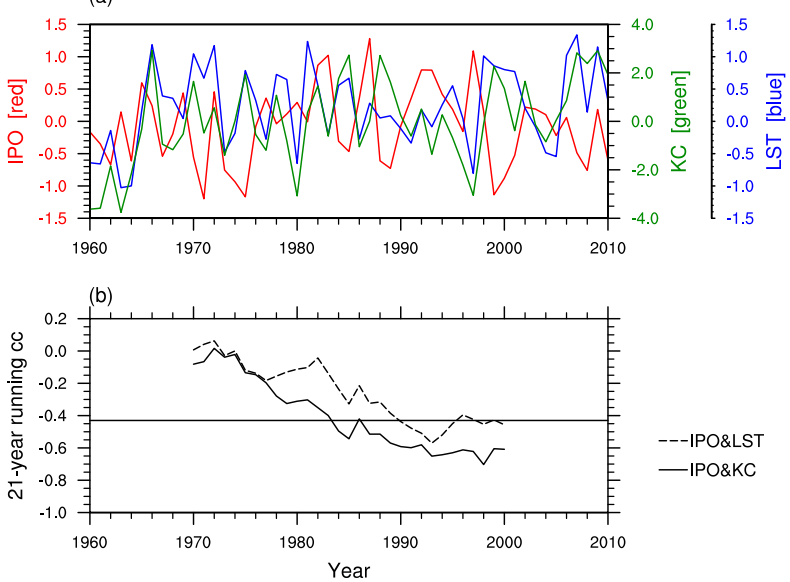

FIG. 10. (a) Red line, green line, and blue line respectively indicate the IPO index (units: ${ }^{\circ} \mathrm{C}$ ), the KC anomaly (units: Sv) $(1 \mathrm{~Sv} \equiv$ $10^{6} \mathrm{~m}^{3} \mathrm{~s}^{-1}$ ), and the LST anomaly (units: Sv). (b) Solid line indicates the 21-yr running correlation coefficient between the IPO index and the KC. Dashed line is the result between the IPO index and the LST.

Why does the LST have different responses to the SSH difference during different periods? Figure 12 shows the regressions of the SSH anomalies onto the IPO index from the SODA analysis and the baroclinic Rossby wave model during P1 and P2. The SSH shows negative and positive anomalies in the western and eastern Pacific corresponding to the IPO, respectively. The scopes of the negative and positive SSH anomalies are wider during P2 than during P1 (Figs. 12a,b). For instance, the northern boundary of the SSH anomalies associated with the IPO in the western Pacific are confined to $12^{\circ} \mathrm{N}$ during P1 (Fig. 12a) but are confined to $20^{\circ} \mathrm{N}$ during P2 (Fig. 12b). The regression coefficients in the western Pacific are larger during P2 than during P1, which indicates that the IPO could influence wider scopes of the SSH anomalies in the western Pacific because of the wider scopes of the wind stress responses during P2. We notice that the modeled SSH anomalies in the SCS are not good compared with the observations, especially during P2 (Figs. 12b,d). The baroclinic Rossby wave model depicts the impacts of the Rossby waves which are driven by the wind stress curl on the SSH variations in the open oceans. This mechanism is not well established in the SCS because the basin scale of the SCS is very small (Cheng et al. 2016). Therefore, the simulated results of the interbasin pressure gradient and the correlations are not adequate in the poor simulation in the SCS (Figs. 12d-f).

The regressions of the SSH anomalies onto the LST from the SODA analysis further show a similar response of the LST to the SSH anomalies during P2 compared
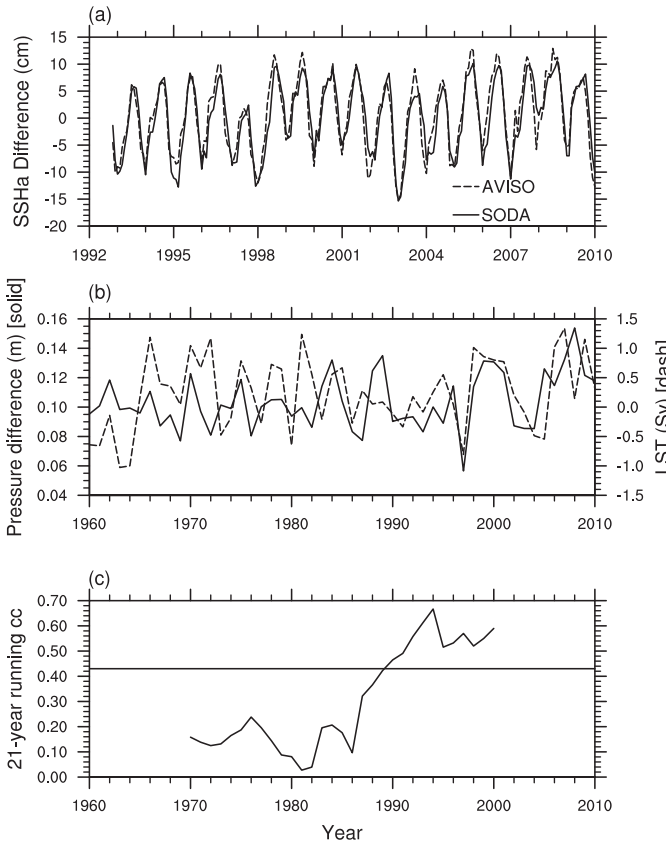
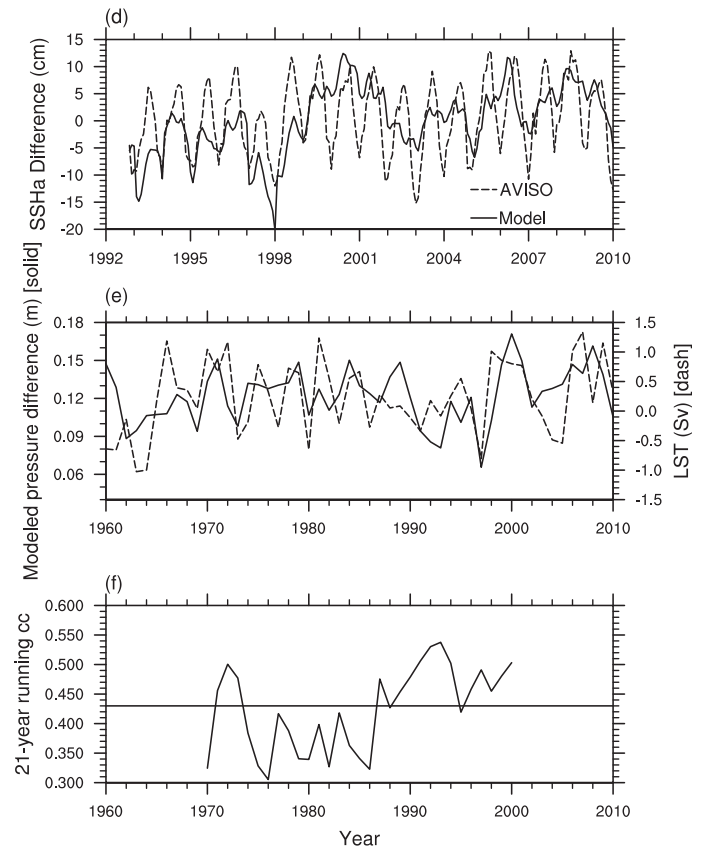

FIG. 11. (a) Solid line and dashed line indicate the monthly SSH difference between the western Pacific and the SCS (climatological SSH has been removed), which are obtained from the SODA reanalysis and AVISO, respectively. (b) Solid line and dashed line indicate the SSH difference in the SODA reanalysis and the LST, respectively. (c) The 21-yr running correlation coefficient between the SSH difference in the SODA reanalysis and the LST. (d)-(f) As in (a)-(c), but the SSH difference is from the baroclinic Rossby wave model simulation. 

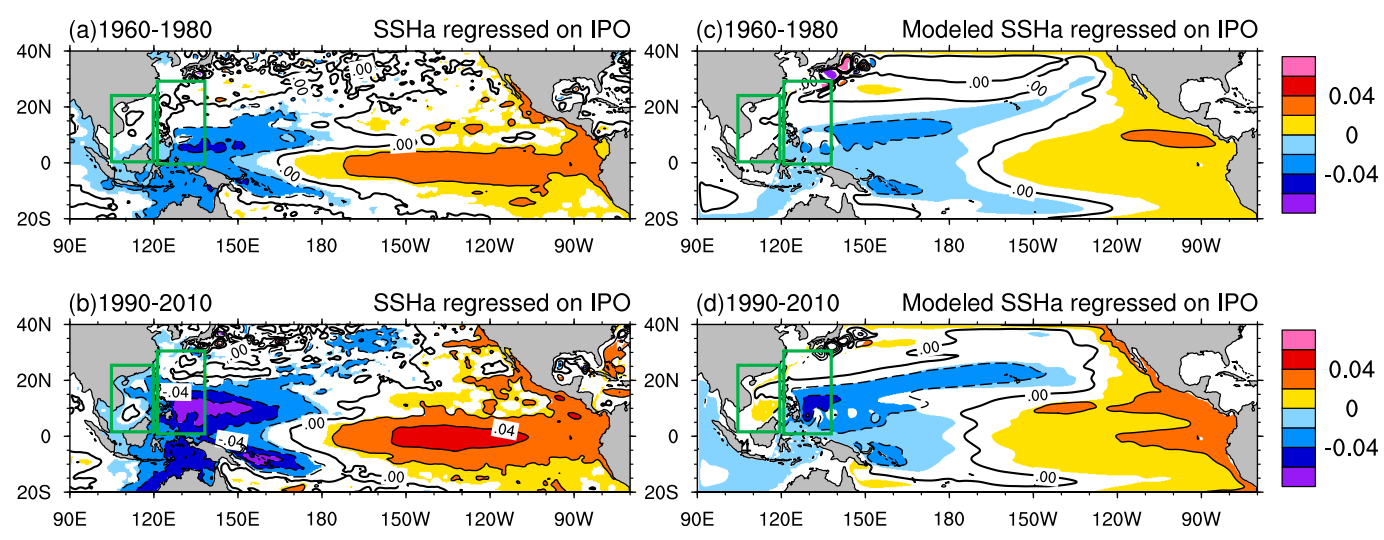

FIG. 12. The regressions of the SSH anomalies onto the IPO index in the SODA analysis during (a) 1960-80 and (b) 1990-2010. (c),(d) As in (a),(b), but for the baroclinic Rossby wave model simulation (units: m). Shading area indicates the regression coefficients exceed the $95 \%$ confidence level based on the Student's $t$ test.

with Fig. 12b, but a smaller response is seen during P1 compared with Fig. 12a (Fig. S8). It is likely that some other processes are the main factors controlling the LST instead of the interbasin pressure gradient, such as the $\mathrm{KC}$. The correlation coefficient between the $\mathrm{KC}$ and LST is 0.88 during P1 but drops to 0.66 during P2. Thus, we can conclude that the main reason for the connection between the LST and the interbasin pressure gradient during P2 could be partially attributed to the wider scope of the wind stress associated with the IPO.

\section{c. Atmospheric process}

D. Wang et al. (2006) connected the LST with the tropical Pacific wind stress through the island rule based on a steady and frictionless Sverdrup theory (Godfrey 1989). Here, we notice that the anomalous wind stress associated with the IPO shows stronger and wider scopes during P2 than during P1 (Figs. 6d-f). The integration of wind stress along the $A B$ pathway is located at $4.75^{\circ} \mathrm{N}$, and the significant zonal wind stress anomalies associated with the IPO are located over $6^{\circ} \mathrm{S}-6^{\circ} \mathrm{N}$ during $\mathrm{P} 1$, the zonal winds around $4.75^{\circ} \mathrm{N}$ are smaller compared with that during $\mathrm{P} 2$, or we can say that the $A B$ pathway could not cross the significant zonal wind stress anomaly area during P1. However, the situation is completely different in that the $A B$ pathway could cross the significant zonal wind stress anomaly area because the significant zonal winds are stronger and wider (approximately $8^{\circ} \mathrm{S}-12^{\circ} \mathrm{N}$ ) during $\mathrm{P} 2$. Then, we use Eq. (2) to confirm this result, and the results are shown in Fig. 13. The positive correlation coefficient between the LST obtained from the SODA reanalysis and island rule indicates that the LST can be partly attributed to the zonal wind stress anomalies over the tropical Pacific. The result of the 21-yr running correlation between these two time series shows that a significant correlation occurred since the 1990s, which is the same period that we discussed before. It illustrates that the atmospheric process is the most direct pathway because the response of the ocean to the wind stress is rapid. These results indicate that, except for the NECBL and the interbasin pressure gradient, the enhanced relationship between the LST and the IPO during P2 could also be explained from the atmospheric bridge perspective.

\section{d. Wave processes}

Rossby waves in the Pacific induced by wind stress anomalies associated with the ENSO or PDO could
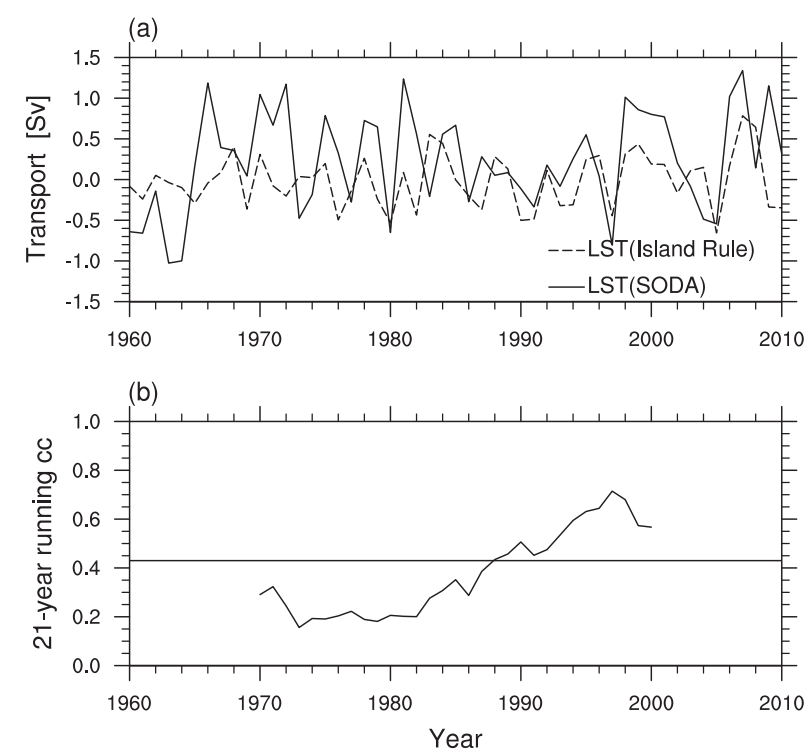

FIG. 13. (a) Solid line and dashed line indicate the LST, which is calculated from the SODA reanalysis and the island rule. (b) Time series of 21-yr running correlation coefficient between the LST from the SODA reanalysis and the island rule. 
(a)

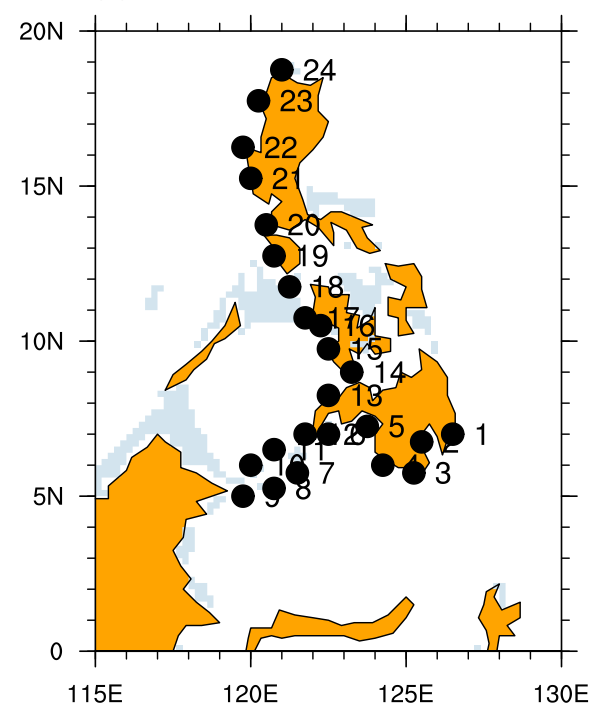

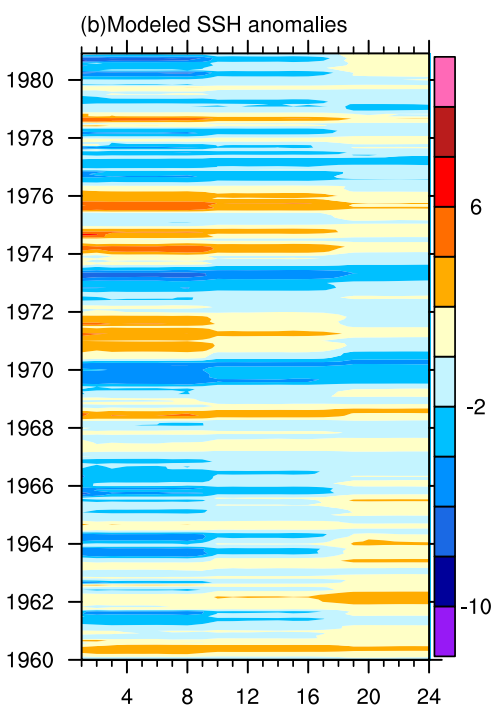

$\begin{array}{cccc}4 & 8 & 12 & 16 \\ \text { (d) SSH anomalies in SODA }\end{array}$
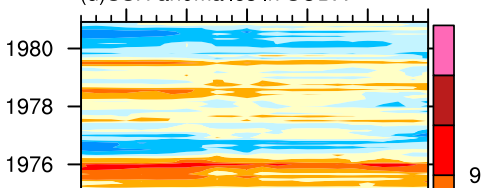

1974

1972

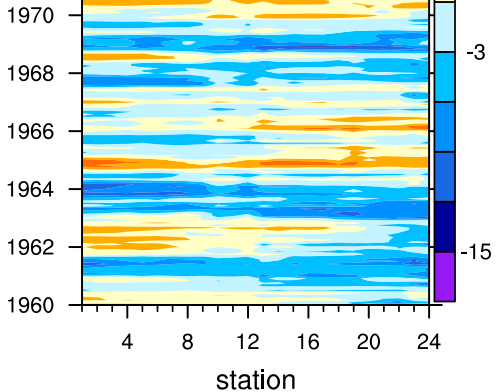

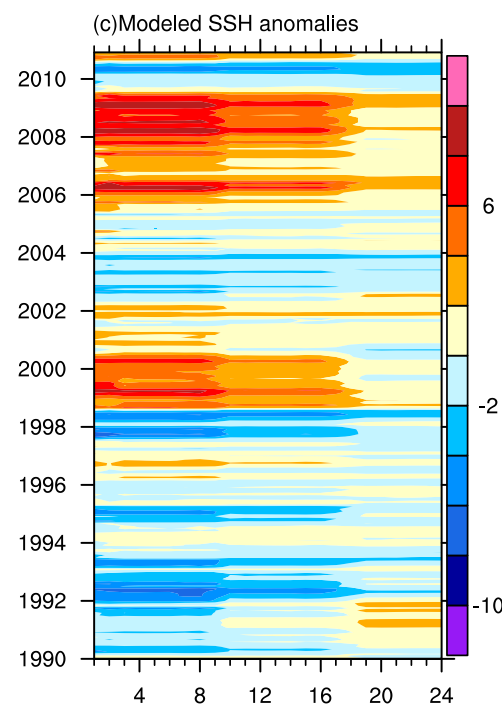

(e)SSH anomalies in SODA

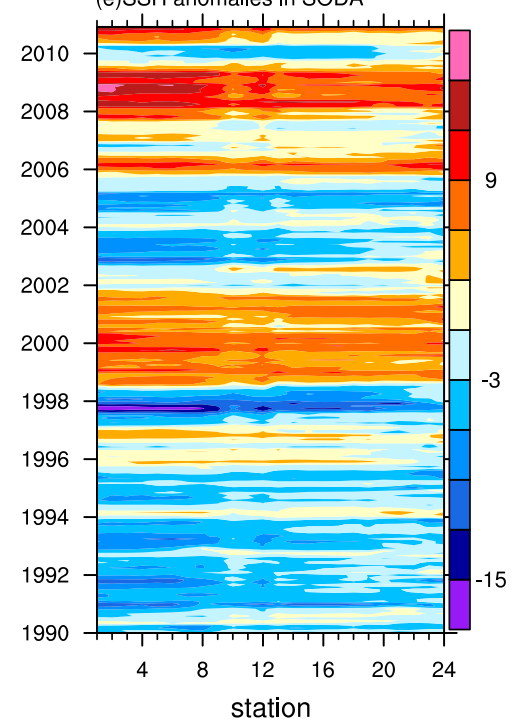

FIG. 14. (a) The waveguide of the coastal Kelvin waves along the west coast of the Philippines from station 1 to 24. (b) Time-station plot of the SSH anomalies along the west coast of the Philippines during 1960-80 (units: cm). (c) As in (b), but for the period of 1990-2010. (d),(e) As in (b),(c), but for the results in the SODA reanalysis.

excite coastal Kelvin waves when they encounter the Philippine Islands, and the coastal Kelvin waves propagate northward along the west coast of the Philippines when they enter the SCS through the Mindoro Strait (Liu et al. 2011; Cheng et al. 2016). In this study, do the influences of the Kelvin wave on the OHC in the SCS vary during different periods? We need to check the propagation characteristics of the coastal Kelvin waves along the west coast of the Philippines during P1 and P2. Figure 14 shows the monthly SSH anomalies along the west coast of the Philippines during P1 and P2 in the model simulation and SODA reanalysis. The modeled SSH anomalies are weaker than those in the SODA reanalysis, especially after Station 18 . This may be caused by differences of the topography in the model and SODA reanalysis, and will not influence the results. The results show that the IPO signal could be transported into the SCS in the form of SSH anomalies but become weaker when the wave signals enter the SCS from Station 18 (Figs. 14b-e). These propagation characteristics of the coastal Kelvin waves seem to have no significant differences between $\mathrm{P} 1$ and $\mathrm{P} 2$. Because of the energy loss in the process of Kelvin wave propagation, the wave process can only affect the OHC in the eastern SCS near Luzon Island, which was also found by Liu et al. (2011) and Zhuang et al. (2013). 


\section{e. Sensitivity experiments}

In addition to the control run, three sensitivity experiments are performed to highlight the effect of the equatorial Pacific wind anomalies. The results of the control run have been compared with the observations before. In the first sensitivity experiment (Exp1), the original monthly wind stress forcing over $8^{\circ} \mathrm{S}-12^{\circ} \mathrm{N}$, $130^{\circ} \mathrm{E}-150^{\circ} \mathrm{W}$ (red box in Fig. S4b) within $2^{\circ}$ linear tapering zones and monthly climatological wind stress forcings over other regions are used to force the model. Exp1 aims to highlight the impact of the wind stress over the key region on the NECBL and LST. In the second sensitivity experiment (Exp2), the monthly climatological wind stress forcing over $8^{\circ} \mathrm{S}-12^{\circ} \mathrm{N}, 130^{\circ} \mathrm{E}-150^{\circ} \mathrm{W}$ and original monthly wind stress forcing over other regions are used to force the model. Exp2 aims to highlight the effect of the wind stress anomalies out of the key region. In the third sensitivity experiment (Exp3), the original monthly wind stress forcing over a narrower region $\left(6^{\circ} \mathrm{S}-6^{\circ} \mathrm{N}, 150^{\circ} \mathrm{E}-150^{\circ} \mathrm{W}\right.$, red box in Fig. S4a) and monthly climatological wind stress forcing over other regions are used to force the model. Exp3 will be compared with Exp1 to highlight the width of the wind stress anomalies.

An enhanced relationship between the NECBL and the IPO could be captured in Exp1, but Exp2 fails to capture this feature (Fig. 15a). These results indicate that the wind stress anomalies over the key region $\left(8^{\circ} \mathrm{S}-\right.$ $12^{\circ} \mathrm{N}, 130^{\circ} \mathrm{E}-150^{\circ} \mathrm{W}$ ) are more important than the outside region for enhancing the relationship. When we use a narrower region $\left(6^{\circ} \mathrm{S}-6^{\circ} \mathrm{N}, 150^{\circ} \mathrm{E}-150^{\circ} \mathrm{W}\right)$ to force the model, we can see a weaker enhanced relationship compared with Exp1. The contributions of the wind forcing over the key region and out of key region in Exp1 and Exp2 can explain about $71 \%(r=0.84)$ and $35 \%(r=0.59)$ of the variances in the interdecadal changes between the NECBL and the IPO after 7-yr low-pass filtering, respectively. The contribution of the wind forcing over the narrower region in Exp3 is almost equal to that in $\operatorname{Exp} 2(36 \% ; r=0.6)$. The results from three sensitivity experiments further indicate that the width of the wind stress anomalies over the key region is crucial for connecting the IPO and the NECBL. These contributions are preliminary estimates based on the simple model and experiments. More accurate relative contributions require an oceanic general circulation model and more sensitivity experiments.

We have discussed that the simulated results of the interbasin pressure gradient are not adequate in the poor simulation in the SCS. The results of the sensitivity experiments show that a similar turning point (approximately 1990) of the 21-yr running correlation occurs
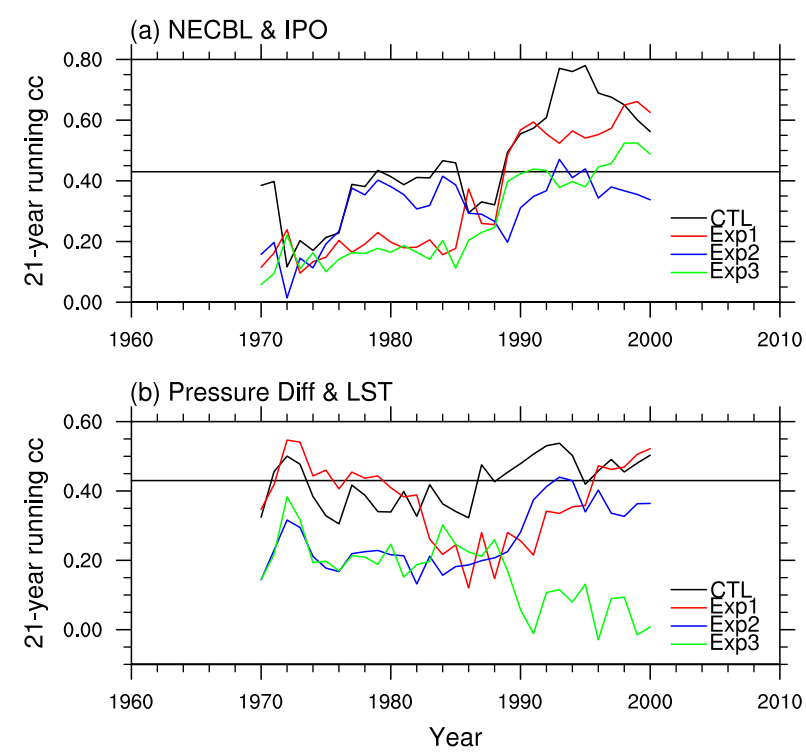

FIG. 15. (a) Time series of 21-yr running correlation coefficient between the IPO index and the NECBL in the control run (black line), Exp1 (red line), Exp2 (blue line), and Exp3 (green line). (b) As in (a), but for the results of interbasin pressure gradient and the LST.

when we consider the wind stress anomalies over the key region $\left(8^{\circ} \mathrm{S}-12^{\circ} \mathrm{N}, 130^{\circ} \mathrm{E}-150^{\circ} \mathrm{W}\right)$ in $\operatorname{Exp} 1$ and only consider other regions in Exp2 (Fig. 15b). The interbasin pressure gradient is defined as the SSH difference between the western Pacific $\left(0^{\circ}-30^{\circ} \mathrm{N}, 122^{\circ}-140^{\circ} \mathrm{E}\right)$ and the $\operatorname{SCS}\left(0^{\circ}-24^{\circ} \mathrm{N}, 105^{\circ}-120^{\circ} \mathrm{E}\right)$. The key region $\left(8^{\circ} \mathrm{S}-12^{\circ} \mathrm{N}\right.$, $130^{\circ} \mathrm{E}-150^{\circ} \mathrm{W}$ ) covers only part of the western Pacific and contributes approximately half of the interbasin pressure gradient from Exp1. When we narrow the region $\left(6^{\circ} \mathrm{S}-6^{\circ} \mathrm{N}, 150^{\circ} \mathrm{E}-150^{\circ} \mathrm{W}\right)$ to force the model, the correlation coefficient decreases to almost zero during P2. These results again highlight the width of the wind stress anomalies over the key region.

\section{Conclusions and discussion}

\section{a. Major conclusions}

In this study, we discussed the interdecadal change in the relationship between the OHC in the SCS and IPO during 1960-2010. The results show that the IPO is highly correlated with the $\mathrm{OHC}$ in the central SCS during P2 (1990-2010), but there is no significant correlation during P1 (1960-80). A schematic diagram is shown in Fig. 16.

During P1, a dipole mode (one pole is located at the SCS and Philippine Seas, and the other pole is located in the central northern Pacific) is a major forcing that controls the $\mathrm{OHC}$ in the SCS during P1. The heat budget analysis results show that both the advection 


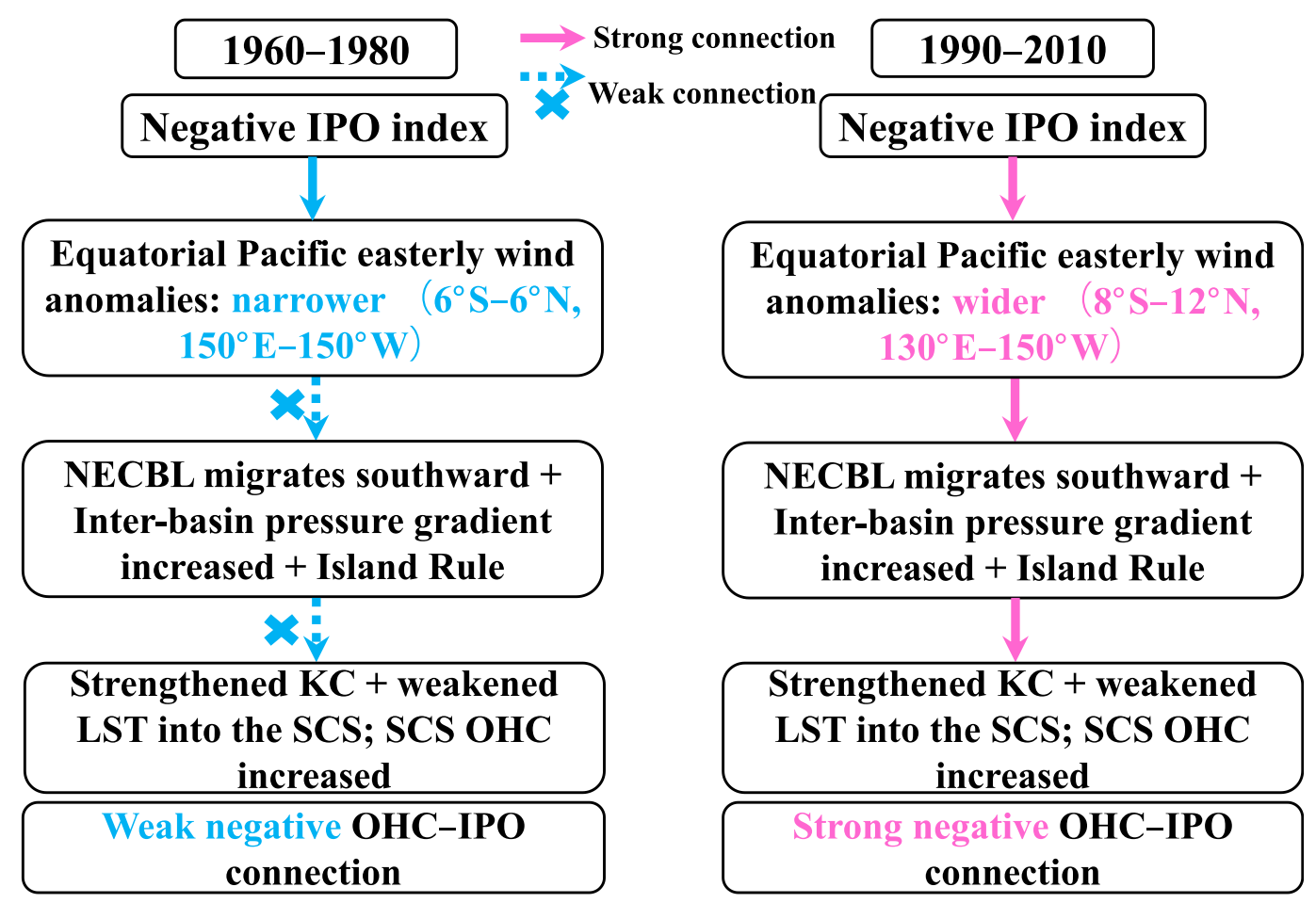

FIG. 16. Schematic diagram of the processes responsible for the enhancing the footprint of the IPO on the OHC in the SCS.

term induced by the oceanic gyre and the net surface heat flux into the SCS are important. When SST anomalies in the SCS are positive and SST anomalies in the Pacific are negative, there exists an anticyclonic circulation over the SCS and Philippine Seas. On the one hand, the anomalous circulation could strengthen the $\mathrm{KC}$ and create an anticyclonic gyre in the SCS, then increase the OHC. On the other hand, the anticyclonic circulation could weaken the annual mean wind speed, and strengthen the positive net surface heat flux into the SCS to increase the OHC.

During P2, the heat budget analysis results show that the advection term induced by the oceanic gyre is the most important factor controlling the OHC in the SCS. The contribution of the net surface heat flux to the OHC decreases and could almost be neglected during P2 compared with that during P1. When the IPO index is negative, the anomalous equatorial Pacific easterly winds are stronger and wider during P2 than during P1. These equatorial Pacific wind anomalies associated with the IPO are the most important factors for enhancing the OHC-IPO connection.

Reanalysis data and model simulations reveal that the scope of the equatorial Pacific wind anomalies is wider during $\mathrm{P} 2$ than during $\mathrm{P} 1$ due to a larger east-west SST gradient and enhanced tropical warming in the Indian Ocean. The wider scope of the equatorial Pacific wind anomalies has three major pathways to influence the $\mathrm{OHC}$ by changing the oceanic gyre in the SCS. First, when the IPO index is negative, the NECBL migrates southward, the KC strengthens, the LST into the SCS weakens, and the OHC in the SCS increases. These results could also be confirmed by the baroclinic Rossby wave model and emphasize the importance of the upper ocean baroclinic response to the wind stress forcing. Second, except for the NECBL, the interbasin pressure gradient between the western Pacific and the SCS is another factor that modulates the $\mathrm{KC}$ according to geostrophic theory. Observational and model results show that when the IPO index is negative, the interbasin pressure gradient between the western Pacific and the SCS increases; thus, it strengthens the $\mathrm{KC}$ and weakens the LST into the SCS, and the OHC in the SCS increases. The wider scope of the SSH responses in the western Pacific during P2 is the main reason for connecting the $\mathrm{OHC}$ and IPO through the interbasin pressure gradient. Last, the equatorial Pacific easterly wind anomalies could weaken the LST into the SCS directly through the island rule because the integrational pathway could cross the significant zonal wind stress anomaly area during P2 but not in P1. The impact of coastal Kelvin wave propagation on the OHC in the SCS has no significant differences between the two periods. All these three pathways for OHC-IPO connection are also 
established after 7-yr low-pass filtering (Figs. S9-S12). All the correlations are significant during P2, whereas they are statistically insignificant during $\mathrm{P} 1$.

Although the regime shift of the OHC in the SCS is attributed to the IPO phase transition during the late 1990s, the strong OHC-IPO connection occurred earlier. This connection bears no relation to the IPO phase transition, and the scope of the equatorial Pacific wind anomalies associated with the IPO is the most important factor for enhancing the OHC-IPO connection. In the three pathways for connecting the OHC and IPO, the island rule is the most direct way of connecting the LST and the IPO during P2. The pathways of wind stress anomalies affecting the NECBL and interbasin pressure gradient through current systems are indirect.

For the discrepancies in the different datasets, we also use an eddy-resolving OGCM for the Earth Simulator (OFES) and NCEP datasets to repeat the analyses, and the same results are also established.

\section{b. Discussion}

In this study, we indicate that the IPO could influence the OHC in the SCS through the LST or SCSTF after the 1990s. Previous studies have shown that the interannual variability in the ITF and the SCSTF is out of phase (Liu et al. 2006, 2010; Wei et al. 2016). The enhanced relationship between the ITF and IPO has also been found; here, the ITF transport is defined as integrating the meridional current over $106^{\circ}-136^{\circ} \mathrm{E}$ in the upper $300 \mathrm{~m}$ at $5^{\circ} \mathrm{S}$ ( $\mathrm{Li}$ et al. 2018). The correlation coefficient between these two variables is 0.72 during P2, but only 0.21 during P1. Previous studies have shown that large impact of the ITF on the upper layer thermodynamics in the southern Indian Ocean (Li et al. 2017, 2018, 2019; Ummenhofer et al. 2017). We re-examined the relationship between the ITF and the upper $300 \mathrm{~m} \mathrm{OHC} \mathrm{in}$ the southeast Indian Ocean during two periods; the results are shown in Fig. S13. Significantly negative regression coefficients are only found during P2, which means that the strong ITF results in upper layer warming of the southeast Indian Ocean, especially along the western Australian coast (Fig. S13b). An increasing frequency of Ningaloo Niño after the 1990s has been observed (Feng et al. 2015), which could be attributed to the enhanced impact of the ITF on the upper $300 \mathrm{~m}$ $\mathrm{OHC}$ in the southeast Indian Ocean, and this requires further study and analysis.

Acknowledgments. F.X. was supported by the National Natural Science Foundation of China under Contract 41806027, D.W. was supported by the Innovative Research Group of the National Natural Science Foundation of China under Contract 41521005, and L.Y. was supported by the National Natural Science Foundation of China under Contract 41676017.

\section{REFERENCES}

Bretherton, C. S., M. Widmann, V. P. Dymnikov, J. M. Wallace, and I. Bladé, 1999: The effective number of spatial degrees of freedom of a time-varying field. J. Climate, 12, 1990-2009, https://doi.org/10.1175/1520-0442(1999)012<1990:TENOSD> 2.0.CO;2.

Carton, J. A., and B. S. Giese, 2008: A reanalysis of ocean climate using Simple Ocean Data Assimilation (SODA). Mon. Wea. Rev., 136, 2999-3017, https://doi.org/10.1175/2007MWR1978.1.

Chelton, D. B., and M. G. Schlax, 1996: Global observations of oceanic Rossby waves. Science, 272, 234-238, https://doi.org/ 10.1126/science.272.5259.234.

Chen, J., C. Chang, and T. Li, 2003: Annual cycle of the South China Sea surface temperature using the NCEP/NCAR reanalysis. J. Meteor. Soc. Japan, 81, 879-884, https://doi.org/ 10.2151/JMSJ.81.879.

Chen, X., and K.-K. Tung, 2014: Varying planetary heat sink led to global-warming slowdown and acceleration. Science, 345, 897903, https://doi.org/10.1126/science.1254937.

Chen, Z., and L. Wu, 2011: Dynamics of the seasonal variation of the North Equatorial Current bifurcation. J. Geophys. Res., 116, C02018, https://doi.org/10.1029/2010JC006664.

— , and —, 2012: Long-term change of the Pacific North Equatorial Current bifurcation in SODA. J. Geophys. Res., 117, C06016, https://doi.org/10.1029/2011JC007814.

Cheng, X., S.-P. Xie, Y. Du, J. Wang, X. Chen, and J. Wang, 2016: Interannual-to-decadal variability and trends of sea level in the South China Sea. Climate Dyn., 46, 3113-3126, https:/ doi.org/10.1007/s00382-015-2756-1.

Chu, P.-C., N. L. Edmons, and C. Fan, 1999: Dynamical mechanisms for the South China Sea seasonal circulation and thermohaline variabilities. J. Phys. Oceanogr., 29, 2971-2989, https://doi.org/10.1175/1520-0485(1999)029<2971:DMFTSC > 2.0.CO;2.

Clarke, A. J., and A. Lebedev, 1996: Long-term change in the equatorial Pacific trade winds. J. Climate, 9, 1020-1029, https:// doi.org/10.1175/1520-0442(1996)009<1020:LTCITE > 2.0.CO;2.

Compo, G., and Coauthors, 2011: The Twentieth Century Reanalysis Project. Quart. J. Roy. Meteor. Soc., 137, 1-28, https://doi.org/ 10.1002/qj. 776 .

Dong, L., and M. J. McPhaden, 2017: Why has the relationship between Indian and Pacific Ocean decadal variability changed in recent decades? J. Climate, 30, 1971-1983, https://doi.org/ 10.1175/JCLI-D-16-0313.1.

Ducet, N., P. Y. Le Traon, and G. Reverdin, 2000: Global highresolution mapping of ocean circulation from TOPEX/ Poseidon and ERS-1 and-2. J. Geophys. Res., 105, $19477-$ 19498, https://doi.org/10.1029/2000JC900063.

England, M. H., and Coauthors, 2014: Recent intensification of wind-driven circulation in the Pacific and the ongoing warming hiatus. Nat. Climate Change, 4, 222-227, https://doi.org/ 10.1038/nclimate2106.

Fang, G., Y. Wang, Z. Wei, Y. Fang, F. Qiao, and X. Hu, 2009: Interocean circulation and heat and freshwater budgets of the South China Sea based on a numerical model. Dyn. Atmos. Oceans, 47, 55-72, https://doi.org/10.1016/j.dynatmoce.2008.09.003.

Feng, J., and D. Hu, 2014: How much does heat content of the western tropical Pacific Ocean modulate the South China 
Sea summer monsoon onset in the last four decades? J. Geophys. Res. Oceans, 119, 4029-4044, https://doi.org/ 10.1002/2013JC009683.

Feng, M., H. H. Hendon, S.-P. Xie, A. G. Marshall, A. Schiller, Y. Kosaka, N. Caputi, and A. Pearce, 2015: Decadal increase in Ningaloo Niño since the late 1990s. Geophys. Res. Lett., 42, 104-112, https://doi.org/10.1002/2014GL062509.

Gao, R., and F. Zhou, 2002: Monsoonal characteristics revealed by intraseasonal variability of sea surface temperature (SST) in the South China Sea (SCS). Geophys. Res. Lett., 29, 1222, https://doi.org/10.1029/2001GL014225.

Godfrey, J. S., 1989: A Sverdrup model of the depth-integrated flow for the world ocean allowing for island circulations. Geophys. Astrophys. Fluid Dyn., 45, 89-112, https://doi.org/ 10.1080/03091928908208894.

Han, W., and Coauthors, 2014: Intensification of decadal and multidecadal sea level variability in the western tropical Pacific during recent decades. Climate Dyn., 43, 1357-1379, https:// doi.org/10.1007/s00382-013-1951-1.

He, Y., and W. B. White, 1987: Interannual variability of the Kuroshio frontal structure along its western boundary in the North Pacific Ocean associated with the 1982 ENSO event. J. Phys. Oceanogr., 17, 1494-1506, https://doi.org/10.1175/ 1520-0485(1987)017<1494:IVOTKF > 2.0.CO;2.

Henley, B. J., J. Gergis, D. J. Karoly, S. Power, J. Kennedy, and C. K. Folland, 2015: A tripole index for the interdecadal Pacific oscillation. Climate Dyn., 45, 3077-3090, https:// doi.org/10.1007/s00382-015-2525-1.

$\mathrm{Hu}, \mathrm{D}$., and Coauthors, 2015: Pacific western boundary currents and their roles in climate. Nature, 522, 299-308, https://doi.org/ 10.1038/nature14504.

Huang, P., I.-I. Lin, C. Chou, and R. Huang, 2015: Change in ocean subsurface environment to suppress tropical cyclone intensification under global warming. Nat. Commun., 6, 7188, https:// doi.org/10.1038/ncomms8188.

Klein, S. A., B. J. Soden, and N. C. Lau, 1999: Remote sea surface temperature variations during ENSO: Evidence for a tropical atmospheric bridge. J. Climate, 12, 917-932, https://doi.org/ 10.1175/1520-0442(1999)012<0917:RSSTVD>2.0.CO;2.

Levitus, S., J. I. Antonov, T. P. Boyer, and C. Stephens, 2000: Warming of the world ocean. Science, 287, 2225-2229, https:// doi.org/10.1126/science.287.5461.2225.

—, J. Wang, T. L. Delworth, K. W. Dixon, and A. J. Broccoli, 2001: Anthropogenic warming of Earth's climate system. Science, 292, 267-270, https://doi.org/10.1126/science.1058154.

Li, L., R. Wu, Y. Li, and Z. Gan, 1999: A preliminary analysis of shallow water tidal aliasing in TOPEX/POSEIDON altimetric data (in Chinese with English abstract). Acta Oceanol. Sin., 21 7-14.

Li, Y., W. Han, and L. Zhang, 2017: Enhanced decadal warming of the southeast Indian Ocean during the recent global surface warming slowdown. Geophys. Res. Lett., 44, 9876-9884, https://doi.org/10.1002/2017GL075050.

,-- , A. Hu, G. A. Meehl, and F. Wang, 2018: Multidecadal changes of the upper Indian Ocean heat content during 19652016. J. Climate, 31, 7863-7884, https://doi.org/10.1175/JCLID-18-0116.1.

$\longrightarrow,-$ L. Zhang, and F. Wang, 2019: Decadal SST variability in the southeast Indian Ocean and its impact on regional climate. J. Climate, 32, 6299-6318, https://doi.org/10.1175/JCLID-19-0180.1.

Liu, Q., X. Jiang, S.-P. Xie, and W.-T. Liu, 2004: A gap in the IndoPacific warm pool over the South China Sea in boreal winter:
Seasonal development and interannual variability. J. Geophys. Res., 109, C07012, https://doi.org/10.1029/2003JC002179.

Liu, Q. Y., R. Huang, D. Wang, Q. Xie, and Q. Huang, 2006: Interplay between the Indonesian Throughflow and the South China Sea Throughflow. Chin. Sci. Bull., 51, 50-58, https:// doi.org/10.1007/s11434-006-9050-x.

—, D. Wang, W. Zhou, Q. Xie, and Y. Zhang, 2010: Covariation of the Indonesian throughflow and South China Sea throughflow associated with the 1976/77 regime shift. Adv. Atmos. Sci., 27, 87-94, https://doi.org/10.1007/s00376-009-8061-3.

- M. Feng, and D. Wang, 2011: ENSO-induced interannual variability in the southeastern South China Sea. J. Oceanogr., 67, 127-133, https://doi.org/10.1007/s10872-011-0002-y.

—, R. Huang, and D. Wang, 2012: Implication of the South China Sea throughflow for the interannual variability of the regional upper-ocean heat content. Adv. Atmos. Sci., 29, 5462, https://doi.org/10.1007/s00376-011-0068-x.

D. Wang, X. Wang, Y. Shu, Q. Xie, and J. Chen, 2014: Thermal variations in the South China Sea associated with the eastern and central Pacific El Niño events and their mechanisms. J. Geophys. Res. Oceans, 119, 8955-8972, https:// doi.org/10.1002/2014JC010429.

Liu, W., S.-P. Xie, and J. Lu, 2016: Tracking ocean heat uptake during the surface warming hiatus. Nat. Commun., 7, 10926, https://doi.org/10.1038/ncomms10926.

Luo, J.-J., W. Sasaki, and Y. Masumoto, 2012: Indian Ocean warming modulates Pacific climate change. Proc. Natl. Acad. Sci. USA, 109, 18701-18 706, https://doi.org/10.1073/pnas.1210239109.

Ma, S., and T. Zhou, 2016: Robust strengthening and westward shift of the tropical Pacific Walker circulation during 19792012: A comparison of 7 sets of reanalysis data and 26 CMIP5 models. J. Climate, 29, 3097-3118, https://doi.org/10.1175/ JCLI-D-15-0398.1.

Nieves, V., J. K. Willis, and W. C. Patzert, 2015: Recent hiatus caused by decadal shift in Indo-Pacific heating. Science, 349, 532-535, https://doi.org/10.1126/science.aaa4521.

North, G. R., T. L. Bell, and R. F. Cahalan, 1982: Sampling errors in the estimation of empirical orthogonal functions. Mon. Wea. Rev., 110, 699-706, https://doi.org/10.1175/1520-0493(1982) $110<0699:$ SEITEO $>2.0$. CO 2 .

Ose, T., Y. Song, and A. Kitoh, 1997: Sea surface temperature in the South China Sea. J. Meteor. Soc. Japan. Ser. II, 75, 10911107, https://doi.org/10.2151/JMSJ1965.75.6_1091.

Pun, I.-F., I.-I. Lin, C.-R. Wu, D. S. Ko, and W.-T. Liu, 2007: Validation and application of altimetry-derived upper ocean thermal structure in the western North Pacific Ocean for typhoon-intensity forecast. IEEE Trans. Geosci. Remote Sens., 45, 1616-1630, https://doi.org/10.1109/TGRS.2007.895950.

Qiu, B., 2002: Large-scale variability in the midlatitude subtropical and subpolar North Pacific Ocean: Observations and causes. J. Phys. Oceanogr., 32, 353-375, https://doi.org/10.1175/15200485(2002)032<0353:LSVITM > 2.0.CO;2.

, and R. Lukas, 1996: Seasonal and interannual variability of the North Equatorial Current, the Mindanao Current, and the Kuroshio along the Pacific western boundary. J. Geophys. Res., 101, 12 315-12 330, https://doi.org/10.1029/95JC03204. , and S. Chen, 2010: Interannual-to-decadal variability in the bifurcation of the North Equatorial Current off the Philippines. J. Phys. Oceanogr., 40, 2525-2538, https:// doi.org/10.1175/2010JPO4462.1.

Qu, T., 2000: Upper-layer circulation in the South China Sea. J. Phys. Oceanogr., 30, 1450-1460, https://doi.org/10.1175/ 1520-0485(2000)030<1450:ULCITS > 2.0.CO;2. 
- 2001: Role of ocean dynamics in determining the mean seasonal cycle of the South China Sea surface temperature. J. Geophys. Res., 106, 6943-6955, https://doi.org/10.1029/ 2000JC000479.

, Y. Y. Kim, M. Yaremchuk, T. Tozuka, A. Ishida, and T. Yamagata, 2004: Can Luzon Strait transport play a role in conveying the impact of ENSO to the South China Sea? J. Climate, 17, 3644-3657, https://doi.org/10.1175/1520-0442(2004) 017<3644:CLSTPA $>2.0$. CO;2.

Rayner, N. A., D. E. Parker, E. B. Horton, C. K. Folland, L. V. Alexander, D. P. Rowell, E. C. Ken, and A. Kaplan, 2003: Global analyses of sea surface temperature, sea ice, and night marine air temperature since the late nineteenth century. J. Geophys. Res., 108, 4407, https://doi.org/10.1029/2002JD002670.

Rong, Z., Y. Liu, H. Zong, and Y. Cheng, 2007: Interannual sea level variability in the South China Sea and its response to ENSO. Global Planet. Change, 55, 257-272, https://doi.org/ 10.1016/j.gloplacha.2006.08.001.

Roxy, M., and Y. Tanimoto, 2012: Influence of sea surface temperature on the intraseasonal variability of the South China Sea summer monsoon. Climate Dyn., 39, 1209-1218, https:// doi.org/10.1007/s00382-011-1118-x.

Shen, S., and K. M. Lau, 1995: Biennial oscillation associated with the East Asian summer monsoon and tropical sea surface temperatures. J. Meteor. Soc. Japan, 73, 105-124, https:// doi.org/10.2151/JMSJ1965.73.1_105.

Sheremet, V., 2001: Hysteresis of a western boundary current leaping across a gap. J. Phys. Oceanogr., 31, 1247-1259, https://doi.org/ 10.1175/1520-0485(2001)031<1247:HOAWBC >2.0.CO;2.

Song, Y. T., 2006: Estimation of interbasin transport using ocean bottom pressure: Theory and model for Asian marginal seas. J. Geophys. Res., 111, C11S19, https://doi.org/ 10.1029/2005JC003189.

Tomita, T., and T. Yasunari, 1996: Role of the northeast winter monsoon on the biennial oscillation of the ENSO/monsoon system. J. Meteor. Soc. Japan, 74, 399-413, https://doi.org/ 10.2151/JMSJ1965.74.4_399.

Ummenhofer, C. C., A. Biastoch, and C. W. Böning, 2017: Multidecadal Indian Ocean variability linked to the Pacific and implications for preconditioning Indian Ocean dipole events. J. Climate, 30, 1739-1751, https://doi.org/10.1175/ JCLI-D-16-0200.1.

von Schuckmann, K., J.-B. Sallée, D. Chambers, P. Y. Le Traon, C. Cabanes, F. Gaillard, S. Speich, and M. Hamon, 2014: Consistency of the current global ocean observing systems from an Argo perspective. Ocean Sci., 10, 547-557, https:// doi.org/10.5194/os-10-547-2014.

Wajsowicz, R. C., 1993: The circulation of the depth-integrated flow around an island with application to the Indonesian Throughflow. J. Phys. Oceanogr., 23, 1470-1484, https://doi.org/ 10.1175/1520-0485(1993)023<1470:TCOTDI > 2.0.CO;2.

Wang, B., R. Wu, and X. Fu, 2000: Pacific-East Asian teleconnection: How does ENSO affect East Asian climate? J. Climate, 13, 1517-1536, https://doi.org/10.1175/1520-0442(2000)013<1517: PEATHD $>2.0 . \mathrm{CO} ; 2$.

Wang, C., 2002: Atmospheric circulation cells associated with the El Niño-Southern Oscillation. J. Climate, 15, 399-419, https://doi.org/ 10.1175/1520-0442(2002)015<0399:ACCAWT>2.0.CO;2.

—, W. Wang, D. Wang, and Q. Wang, 2006: Interannual variability of the South China Sea associated with El Niño. J. Geophys. Res., 111, C03023, https://doi.org/10.1029/2005JC003333.

Wang, D., Q. Liu, R. Huang, Y. Du, and T. Qu, 2006: Interannual variability of the South China Sea throughflow inferred from wind data and an ocean data assimilation product. Geophys. Res. Lett., 33, L14605, https://doi.org/10.1029/2006GL026316.

Wang, G., J. Su, Y. Ding, and D. Chen, 2007: Tropical cyclone genesis over the South China Sea. J. Mar. Syst., 68, 318-326, https://doi.org/10.1016/j.jmarsys.2006.12.002.

Wang, L., C. Wu, and B. Qiu, 2014: Modulation of Rossby waves on the Pacific North Equatorial current bifurcation associated with the 1976 climate regime shift. J. Geophys. Res. Oceans, 119, 6669-6679, https://doi.org/10.1002/2014JC010233.

Wang, T., Y. Du, W. Zhuang, and J. Wang, 2015: Connection of sea level variability between the tropical western Pacific and the southern Indian Ocean during recent two decades. Sci. China Earth Sci., 58, 1387-1396, https://doi.org/10.1007/s11430-0145048-4.

Wang, X., B. Tong, D. Wang, and L. Yang, 2019: Variations of the North Equatorial Current bifurcation and the SSH in the western Pacific associated with El Niño flavors. J. Geophys. Res. Oceans, 125, e2019JC015733, https://doi.org/10.1029/ 2019JC015733.

Wei, J., M. Li, P. Malanotte-Rizzoli, A. L. Gordon, and D. Wang, 2016: Opposite variability of Indonesian Throughflow and South China Sea throughflow in the Sulawesi Sea. J. Phys. Oceanogr., 46, 3165-3180, https://doi.org/10.1175/JPO-D-160132.1.

Williams, A., and C. Funk, 2011: A westward extension of the warm pool leads to a westward extension of the Walker circulation, drying eastern Africa. Climate Dyn., 37, 2417-2435, https:// doi.org/10.1007/s00382-010-0984-y.

$\mathrm{Wu}, \mathrm{R}$., and Z. Chen, 2015: Intraseasonal SST variations in the South China Sea during boreal winter and impacts of the East Asian winter monsoon. J. Geophys. Res. Atmos., 120, 58635878, https://doi.org/10.1002/2015JD023368.

Xiang, B., B. Wang, J. Li, M. Zhao, and J.-Y. Lee, 2014: Understanding the anthropogenically forced change of equatorial Pacific trade winds in coupled climate models. J. Climate, 27, 8510-8526, https://doi.org/10.1175/JCLI-D14-00115.1.

Xiao, F., L. Zeng, Q.-Y. Liu, W. Zhou, and D. Wang, 2018: Extreme subsurface warm events in the South China Sea during 1998/99 and 2006/07: Observations and mechanisms. Climate Dyn., 50, 115-128, https://doi.org/10.1007/S00382-0173588-Y.

_ D. D. Wang, L. Zeng, Q.-Y. Liu, and W. Zhou, 2019: Contrasting changes in the sea surface temperature and upper ocean heat content in the South China Sea during recent decades. Climate Dyn., 53, 1597-1612, https://doi.org/10.1007/s00382-019-04697-1.

Xie, S.-P., Q. Xie, D. Wang, and W.-T. Liu, 2003: Summer upwelling in the South China Sea and its role in regional climate variations. J. Geophys. Res., 108, 3261, https://doi.org/10.1029/ 2003JC001867.

— C. Deser, G. A. Vecchi, J. Ma, H. Teng, and A. T. Wittenberg, 2010: Global warming pattern formation: Sea surface temperature and rainfall. J. Climate, 23, 966-986, https://doi.org/10.1175/2009JCLI3329.1.

Yan, Y., Y. Qi, and W. Zhou, 2010: Interannual heat content variability in the South China Sea and its response to ENSO. Dyn. Atmos. Oceans, 50, 400-414, https://doi.org/10.1016/ j.dynatmoce.2010.07.002.

Yu, K., and T. Qu, 2013: Imprint of the Pacific decadal oscillation on the South China Sea throughflow variability. J. Climate, 26, 9797-9805, https://doi.org/10.1175/JCLI-D-12-00785.1.

Zeng, L., D. Wang, J. Chen, W. Wang, and R. Chen, 2016: SCSPOD14, a South China Sea physical oceanographic dataset 
derived from in situ measurements during 1919-2014. Sci. Data, 3, 160029, https://doi.org/10.1038/sdata.2016.29.

Zhai, X., and L. Sheldon, 2012: On the North Atlantic Ocean heat content change between 1955-70 and 1980-95. J. Climate, 25, 3619-3628, https://doi.org/10.1175/JCLI-D-11-00187.1.

Zhang, L., 2016: The roles of external forcing and natural variability in global warming hiatuses. Climate Dyn., 47, 31573169, https://doi.org/10.1007/s00382-016-3018-6.
- W. Han, and F. Sienz, 2018: Unraveling causes for the changing behavior of the tropical Indian Ocean in the past few decades. J. Climate, 31, 2377-2388, https://doi.org/10.1175/ JCLI-D-17-0445.1.

Zhuang, W., B. Qiu, and Y. Du, 2013: Low-frequency western Pacific Ocean sea level and circulation changes due to the connectivity of the Philippine Archipelago. J. Geophys. Res. Oceans, 118, 6759-6773, https://doi.org/10.1002/2013JC009376. 